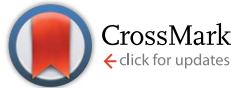

Cite this: RSC Adv., 2017, 7, 15536

Received 25th November 2016 Accepted 10th February 2017

DOI: 10.1039/c6ra27314a

rsc.li/rsc-advances

\section{Efficient rejection of organic compounds using functionalized ZSM-5 incorporated PPSU mixed matrix membrane}

\author{
R. Saranya, ${ }^{a}$ G. Arthanareeswaran, ${ }^{\star a}$ A. F. Ismail, ${ }^{b}$ N. Lakshmana Reddy, ${ }^{c}$ M. V. Shankar ${ }^{c}$ \\ and Jihyang Kweon ${ }^{d}$
}

Zeolite (ZSM-5) and functionalised zeolite blended polyphenylsulfone (PPSU) mixed matrix membranes (MMMs) were fabricated for comparing their performance with virgin PPSU. Similar to zeolite-MMMs, functionalised zeolites such as Fe-ZSM-5 (Fe-Z) and Cu-ZSM-5 (Cu-Z) were mixed with PPSU in the presence of $\mathrm{N}$-methyl pyrrolidone (NMP) solvent. The synthesized zeolite nanoparticles were ultrasonicated before incorporation to ensure uniform dispersion in PPSU. The PPSU MMMs with incorporated nanomaterials were fabricated as flat sheet modules by means of the phase inversion method. The developed MMMs were examined for homogeneity and characterized for their properties, such as surface hydrophilicity, membrane morphology, thermal stability and surface roughness. An enhanced pure water flux of $62 \mathrm{~L} \mathrm{~m}^{-2} \mathrm{~h}^{-1}$ and a highest lignin retention of $85.2 \%$ were observed for a PPSU membrane with $0.5 \mathrm{wt} \%$ of zeolite nanomaterials incorporated. The 3D porous structure of the zeolite favoured the enhancement of flux during water and lignin separation. However, the incorporation of functionalised zeolite nanomaterials influenced the increase in maximum lignin rejection to $88.5 \%$. The performance and anti-fouling ability of synthesized MMMs has been evaluated based on the rejection of organic components. Higher preferential permeation with great rejection of lignin were simultaneously observed for zeolite and $\mathrm{Cu}$-zeolite incorporated MMMs.

\section{Introduction}

The progress of membrane technology necessitates robust membrane materials with controllable separation performance, fouling resistance and long term stability. ${ }^{1}$ Mixed Matrix Membranes (MMMs) have numerous advantages over traditional polymeric membranes as they encompass the synergistic combination of inorganic and organic phases. The formation of MMMs by means of blending the polymeric membrane with inorganic materials has much potential to improve the membrane performance. ${ }^{2}$ The specific role of organic and inorganic components as well as their synergistic effect on the performance of MMMs depends on the properties of the inorganic materials and their functionalities. In contrast to inorganic solid fillers, novel MMMs are proposed using nano-size

${ }^{a}$ Membrane Research Laboratory, Department of Chemical Engineering, National Institute of Technology, Tiruchirapalli-620015, Tamil Nadu, India. E-mail: arthanaree10@yahoo.com; Fax: +91-431-2500133; Tel: +91-431-2503118

${ }^{b}$ Advanced Membrane Technology Research Centre (AMTEC), Universiti Teknologi Malaysia, 81310 UTM, Skudai, Johor, Malaysia

${ }^{c}$ Nano Catalysis and Solar Fuels Research Laboratory, Department of Materials Science \& Nanotechnology, Yogi Vemana University, Vemanapuram, Kadapa-516003, Andhra Pradesh, India

${ }^{d}$ Department of Environmental Engineering, Konkuk University, Seoul, Republic of Korea particles as inorganic fillers in a continuous polymer matrix. ${ }^{3}$ The rapid growth of nanotechnology has meant a great deal of interest in the use of nanomaterials in the formation of MMMs. Nanomaterials are excellent adsorbents and catalysts due to their large specific surface areas and high reactivity. ${ }^{4}$ Nanosized inorganic material blended MMMs are attractive in the field of membrane science because of their enhanced properties such as high permselectivity, thermal stability and enhanced fouling resistance. ${ }^{5}$ However, the challenge in the use of nanoparticles as inorganic fillers has been their incorporation into MMMs. ${ }^{6,7}$

MMMs composed of inorganic nanomaterials are being developed due to their higher durability and performance in many separation applications. ${ }^{8,9}$ These organic-inorganic hybrid membranes are expected to be a new generation of high performance membranes, possessing the merits of both organic membranes (permeability and pliability) and inorganic membranes (selectivity and stability). ${ }^{10}$ There has been reported evidence on the role of nanoparticles in MMMs for achieving much higher selectivity without compromising the flux. ${ }^{11,12}$ As the selectivity is linked to parameters such as polymer-free volume, particle size and surface, and the presence of covalent bonding, ${ }^{13}$ it is expected that by mixing the nano-size particles with the polymer, the accessible free volume in the polymer matrix might be further increased. Recently, we have 
reported a functionalized protonic trititanate nanotube-PEI nanocomposite membrane for an improved salt rejection application. ${ }^{14}$

Use of nanomaterials plays a key role in improving membrane characteristics such as increased porosity, enhanced hydrophilicity and improved fouling resistance. ${ }^{15}$ The alteration in pore morphology is due to the incorporated nano-porous materials being able to prevent the passage of a range of contaminants through the MMM during the treatment operation. ${ }^{16}$ These advances have motivated the exploration of novel inorganic nanomaterials in the fabrication of tailor-designed MMMs. On the other hand, the effect of MMMs on liquid filtration has only been studied to a limited extent. ${ }^{17}$ Thus the need for improvements in the performance of membrane properties for effluent treatment has motivated the search for robust MMMs by incorporating novel inorganic nanomaterials, thereby resulting in (1) desired morphology and surface properties, (2) improved permeability and rejection ability and (3) higher fouling resistant capacity during rejection of organic pollutants from the effluent. It is also evident from the reviewed literature that UF membrane properties can be tailored by employing the MMM approach. ${ }^{18,19}$ Nanoparticle-based membranes can be fabricated by assembling nanoparticles on porous membranes or by blending them with polymeric or inorganic membranes. ${ }^{20}$ However, the fundamental relationships between inorganic filler material size, chemical composition, and structure and the transport, structural, mechanical and interfacial properties of the resulting MMMs are not well understood. ${ }^{21}$ In an attempt to begin elucidating the fundamentals of mixed-matrix UF membranes and to develop more fouling resistant UF membranes, different inorganic fillers including different zeolite molecular sieves and metal nanoparticles are being studied. ${ }^{22}$ Recently, a nanoparticle doped MMM has generated considerable interest., ${ }^{9,23}$ The presence of inorganic charged nanoparticles in the membrane matrix has potential application in wastewater treatment. Similarly, an increase in inorganic nanomaterial concentration may result in the formation of many interfacial defects in the skin layer which implies the importance of the ratio of polymer to inorganic for membrane formation. ${ }^{24}$

Zeolites are microporous crystalline alumina-silicate materials, routinely used as catalysts, ion-exchangers and adsorbents because of their chemical structure and surface properties. ${ }^{25}$ The unique pore structure and sharp pore size distribution of zeolites can be used for membrane fabrication by incorporating them into a polymer for better performance by means of molecular sieving and selective adsorption. ${ }^{26}$ Metal functionalised zeolites have been considered to be one of the most selective inorganic membrane materials. In the preparation of a mixed matrix membrane, the uniform distribution of the nanoparticles in the polymer matrix is a very great task. Fe-ZSM5 and $\mathrm{Cu}-\mathrm{ZSM}-5$ were selected as modifiers, because the incorporation of $\mathrm{Fe}$ and $\mathrm{Cu}$ into the zeolite framework has attracted much interest because it provides a novel way of obtaining high dispersions within the zeolite structure. Further, $\mathrm{Fe}$ and $\mathrm{Cu}$ ions could uniformly disperse deep into the zeolite channels. By employing zeolite (ZSM-5) and functionalised zeolites such as
Fe-ZSM-5 and Cu-ZSM-5, an appropriate pore structure can be formed so as to exclude the solute to be retained with an increase in permeability. ${ }^{27}$ Such enhanced rejection combined with increased permeability were realized by incorporating a silicate based zeolite in studies pertaining to NF and RO membranes. ${ }^{28}$ More experimental and theoretical studies are needed for a fundamental understanding of the interaction of zeolite nanoparticles with different polymer matrixes during membrane formation, and also studies on the effect of crystal and pore structure and sizes of zeolites on the membrane structure and transport properties. Such an understanding will be crucial for the design and fabrication of a new class of MMMs. ${ }^{29}$ Several reports exist on different types of zeolite based membranes, but there are only limited reports on functionalised zeolite impregnated polymeric membranes with importance for wastewater treatment applications. ${ }^{11,12,28}$ Hence, ZSM5, Fe-ZSM-5, Cu-ZSM-5 incorporated polyphenylsulfone (PPSU) is fabricated in this study with a view to improving the membrane performance. The synthesized PPSU MMMs have been evaluated in terms of hydrophilicity, morphology, roughness and homogeneity. Their performance has also been investigated based on the filtration of lignosulfonate as a foulant for which a fouling analysis has been done. The antifouling properties and rejection ability were compared with virgin PPSU.

\section{Experimental}

\subsection{Synthesis of functionalised ZSM-5}

The functionalised zeolites such as Cu-ZSM-5 and Fe-ZSM-5 were supplied by Sud-chemie (India) Ltd., by the ion-exchange method using respective precursors of metal salts. In a typical procedure, zeolite $(0.5 \mathrm{~g})$ was suspended in $0.05 \mathrm{M}$ of $\mathrm{Cu}\left(\mathrm{NO}_{3}\right)_{2}$ aqueous solution in a $250 \mathrm{~mL}$ beaker and stirred well at $500 \mathrm{rpm}$. After $2 \mathrm{~h}$ of stirring, the suspension was filtered under a vacuum and washed thoroughly with an excess amount of distilled water until the nitrate had been washed off. The thus obtained light blue coloured precipitate of Cu-ZSM- 5 was dried in a hot air oven at $80^{\circ} \mathrm{C}$ for $12 \mathrm{~h}$. For the synthesis of Fe-ZSM-5, a similar procedure was followed for a complete suspension of $0.5 \mathrm{M}$ of $\mathrm{FeCl}_{3}$ aqueous solution and the obtained Fe-ZSM-5 precipitate was dried in a hot air oven at $80^{\circ} \mathrm{C}$ for $12 \mathrm{~h}$.

\subsection{Characterisation of zeolite and functionalised zeolite}

The synthesized nanomaterials were characterised for their morphology, particle size and chemical structure and zeta potential. The synthesized nanomaterials were then characterised for their particle size using a particle size analyser (Nanopartica, Hiroba, USA). The zeta potential was measured by electrophoretic mobility measurements using a Malvern Zetasizer NanoZS (Malvern Instruments Ltd, Worcestershire, UK). The crystallite phase and particle size were also studied by means of an X-ray diffractogram (XRD, Rigaku Corporation, Japan). The particle size $(D)$ was also found with the help of the following Scherrer eqn (1): 


$$
D=\frac{0.9 \lambda}{\beta \cos \theta}
$$

where $\lambda$ is the $\mathrm{X}$-ray wavelength and $\beta$ is the full-width half maximum (FWHM) of the intensity peak at the corresponding Braggs diffraction angle $(\theta)$.

\subsection{Synthesis of zeolite and functionalised zeolite incorporated PPSU MMMs}

To develop PPSU MMMs by incorporating ZSM-5, Cu-ZSM-5 and Fe-ZSM-5, there are three important steps, as elaborated below:

2.3.1. Ultrasonication of nanomaterial. The nanomaterials such as ZSM, Cu-ZSM-5 and Fe-ZSM-5 were initially dispersed well in $N$-methyl pyrrolidone (NMP) solvent with the help of sonication waves in an ultra-sonication bath (Sonics) maintained at $30{ }^{\circ} \mathrm{C}$ for $15 \mathrm{~min}$.

2.3.2. Preparation of casting solution. The second step is the preparation of a casting solution by the physical blending of the respective nanomaterials with PPSU under mechanical stirring. The compositions of the casting solution for the synthesis of zeolite and functionalised zeolite based MMMs are given in Table 1. In Table 1, a $17.5 \mathrm{wt} \%$ PPSU membrane is denoted as virgin PPSU. The increments in ZSM-5 nanomaterials are from $0.25,0.5,0.75$ to $1 \mathrm{wt} \%$ in $17.5 \mathrm{wt} \%$ of PPSU, the membranes being denoted as PP/Ze-1 MMM, PP/Ze-2 MMM, $\mathrm{PP} / \mathrm{Ze}-2 \mathrm{MMM}$ and PP/Ze-4 MMM, respectively. Amounts of 0.25 and $0.5 \mathrm{wt} \%$ of Cu-ZSM-5 were added to PPSU and denoted as $\mathrm{PP} / \mathrm{Cu}-\mathrm{Ze}-1 \mathrm{MMM}$ and $\mathrm{PP} / \mathrm{Cu}-\mathrm{Ze}-2 \mathrm{MMM}$, respectively. Similarly, 0.25 and $0.5 \mathrm{wt} \%$ of Fe-ZSM- 5 were incorporated into PPSU and the membranes are denoted as PP/Fe-Ze-1 MMM and PP/ Fe-Ze-2 MMM, respectively.

2.3.3. Membrane fabrication by phase inversion. The homogeneous solution formed in the previous step was allowed to stand at room temperature to eliminate air bubbles. Before being cast, the solution mix was again sonicated for $30 \mathrm{~min}$. The solution was cast into a thin film of $400 \mu \mathrm{m}$ thickness over a clean, levelled glass plate using a stainless steel film applicator (Elcometer, Mumbai) at room temperature. Then the film was kept for the partial evaporation of the solvent for about 30 seconds and later quenched in a gelation bath maintained at $10{ }^{\circ} \mathrm{C}^{30}$ The experimental conditions for performing the phase inversion method of membrane formation are given in Table 2.
The PP/ZSM-5, PP/Cu-Ze and PP/Fe-Ze MMMs thus formed were left in the water for $24 \mathrm{~h}$. The resultant membranes were stored in $1 \%$ formalin solution to preserve them from any microbial growth.

\subsection{Characterisation of zeolite and functionalised zeolite incorporated PPSU MMMs}

2.4.1. XRD analysis of zeolite and functionalised zeolite incorporated PPSU MMMs. XRD patterns were obtained for synthesized MMMs using a powder X-ray diffractometer (D8 234 advance, Bruker, Germany) equipped with a monochromatic nickel-filtered $\mathrm{Cu} \mathrm{K} \alpha$ radiation source $(40 \mathrm{kV}, 30 \mathrm{~mA})$ with a scintillation counter ( $\mathrm{Nal}$ ) as the detector. From the XRD pattern, the MMMs were analysed based on a comparison of peak intensity with respect to the diffraction angle and crystallite size. The membrane surface charge was determined ${ }^{31}$ by zeta potentials and streaming potential measurements carried out in the SurPASS system (Anton Paar, Graz, Austria).

2.4.2. Hydrophilicity of zeolite and functionalised zeolite incorporated PPSU MMMs. The surface hydrophilic properties of the synthesized PPSU MMMs were examined for contact angle analysis using a contact angle goniometer (model 250-F1, Rame-Hart Instruments, New Jersey) at room temperature. The static sessile drop method was employed in which the water droplet was introduced by means of a syringe onto the surface of the membranes to determine the average equilibrium water contact angle. ${ }^{32}$ The means of the left and right contact angles resulted in the equilibrium water contact angle and measurements were taken at five different locations to get the average equilibrium water contact angles of the respective membranes. The surface free energy of interaction of water and the membrane surface $\left(\Delta G_{\mathrm{s}}\right)$ was also interpreted based on the Young-Dupre eqn (2). ${ }^{33}$

$$
\Delta G_{\mathrm{s}}=(1+\cos \theta) \gamma_{\mathrm{L}}^{\mathrm{T}}
$$

where $\theta$ denotes the measured water contact angle and $\gamma_{\mathrm{L}}^{\mathrm{T}}$ denotes the water surface tension $\left(72.8 \mathrm{~mJ} \mathrm{~m}^{-2}\right)$.

2.4.3. Morphological studies of zeolite and functionalised zeolite incorporated PPSU MMMs. The top and cross section morphology of the synthesized PPSU MMMs were examined using a field emission scanning electron microscope (SUPRA-

Table 1 Casting solution composition of zeolite and functionalised zeolite PPSU MMMs

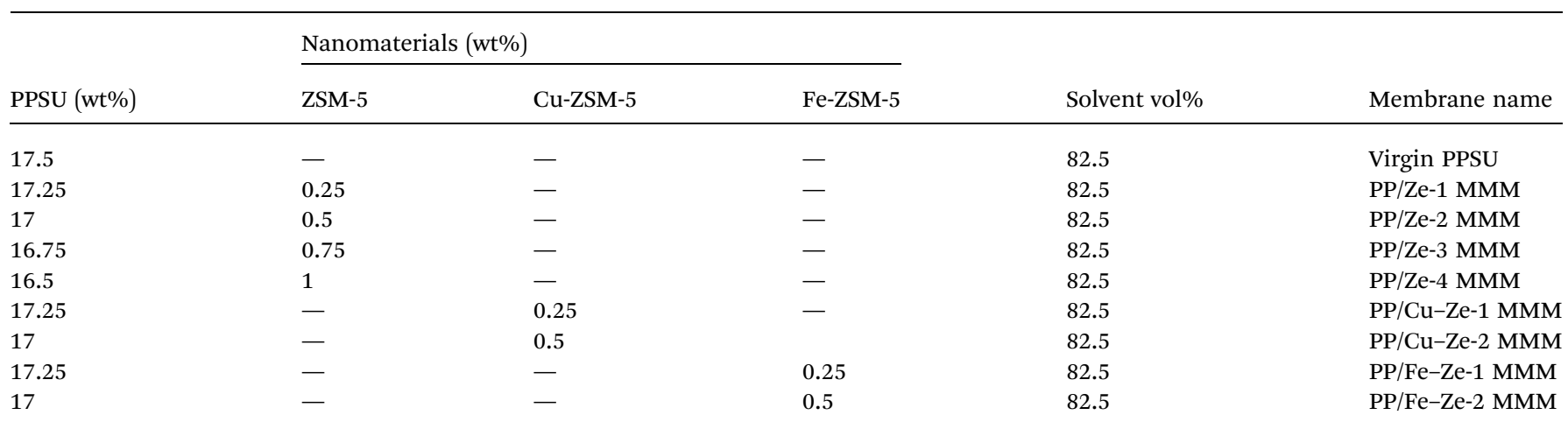


Table 2 Experimental conditions for developing PPSU MMMS

\begin{tabular}{lll}
\hline Fabrication steps & Conditions & Temperature \\
\hline Ultrasonication & 30 min at intervals of twice & $32{ }^{\circ} \mathrm{C}$ \\
Casting solution & Mechanical stirring for $3 \mathrm{~h}$ & $45 \pm 2{ }^{\circ} \mathrm{C}$ \\
& Degassing & Vacuum oven $60{ }^{\circ} \mathrm{C}$ \\
Phase inversion & Cooling & Room temperature $27 \pm 2{ }^{\circ} \mathrm{C}$ \\
& Membrane casting in glass plate & $20 \pm 2{ }^{\circ} \mathrm{C}$ and relative humidity $50 \%$ \\
& Evaporation & $30 \mathrm{~s}$ \\
& Gelation bath (water with $0.2 \mathrm{wt} \%$ of SLS and 1 vol\% of NMP) & $10{ }^{\circ} \mathrm{C}$
\end{tabular}

55, Carl Zeiss, Germany). For the cross-sectional views, the membranes were prepared by fracturing in liquid nitrogen. The membranes were initially pre-treated with gold $\mathrm{(Au}$ ) sputtering to impart electrical conductivity to get better visibility of the surface and pore morphology. For analysis, an accelerating voltage of $20 \mathrm{kV}$ was fixed with a field emission resolution of 20 $\mu \mathrm{m}$.

2.4.4. Roughness analysis of zeolite and functionalised zeolite incorporated PPSU MMMs. The surface topography of the PPSU MMMs was examined using non-contact mode atomic force microscopy (NT-MDT modular AFM, NTEGRA Prima, Ireland). High resolution two and three dimensional surface images were taken for a comparison of surface roughness between virgin and modified membranes. With the help of Nova-NTEGRA AFM software, the images were processed with a sample scan area of $30 \mu \mathrm{m} \times 30 \mu \mathrm{m}$ for measuring average roughness $\left(R_{\mathrm{a}}\right)$ and root-mean-squared roughness $\left(R_{\mathrm{rms}}\right)$ values for each membrane. The $R_{\mathrm{rms}}$ can be determined based on the standard deviation of the data points ${ }^{34}$ observed across the scan as shown below in eqn (3):

$$
R_{\mathrm{rms}}=\sqrt{\frac{\sum_{n=1}^{N}\left(z_{n}-\bar{z}\right)^{2}}{N-1}}
$$

where $\bar{z}$ is the average value of $z$ in a given area and $z_{n}$ is the current $z$ value and $N$ is the number of data points.

2.4.5. Mean pore size of zeolite and functionalised zeolite incorporated PPSU MMMs. The porosity $(\varepsilon)$ of each synthesized membrane was found to measure the mean pore radius $\left(r_{\mathrm{m}}\right)$ based on the filtration velocity method. The experimental determination of $r_{\mathrm{m}}$ using the Guerout-Elford-Ferry equation is given as follows:

$$
\text { Pore radius }\left(r_{\mathrm{m}}\right)=\sqrt{\frac{(2.9-1.75 \varepsilon) \times 8 \eta \iota Q}{\varepsilon \times A \times \Delta P}}
$$

where $\eta$ is the viscosity of water $\left(8.9 \times 10^{-4} \mathrm{~Pa} \mathrm{~s}\right), \iota$ is the membrane thickness $(400 \mu \mathrm{m}), Q$ is the permeate volume per unit time $\left(\mathrm{m}^{3} \mathrm{~s}^{-1}\right), A$ is the effective membrane area $\left(38.5 \mathrm{~cm}^{2}\right)$ and $\Delta P$ is the operational pressure $(414 \mathrm{kPa})$.

\subsection{Permeation studies}

Pure water flux studies were carried out using a constantvolume, variable-pressure UF stirred dead end flow cell (model Cell-XFUF076, Millipore, USA) fitted with a Teflon coated magnetic paddle. The permeability of each synthesized membrane was measured by initially compacting it under a trans-membrane pressure (TMP) of $414 \mathrm{kPa}$ until a steady permeate volume was collected. The effective membrane surface area of the employed membranes was kept at $38.5 \mathrm{~cm}^{2}$. The volume permeated corresponding to each membrane was noted under steady state conditions for $10 \mathrm{~min}$ at room temperature and the initial water flux $\left(J_{\mathrm{w} 1}\right)$ of each membrane was quantified based on the following eqn (5):

$$
J_{\mathrm{w}}=\frac{V}{A \times \Delta t}
$$

where $V$ is the volume of filtered water $\left(\mathrm{m}^{3}\right), A$ is the membrane area $\left(\mathrm{m}^{2}\right)$ and $\Delta t$ is the working time $(\mathrm{h})$.

\subsection{Performance evaluation of zeolite and functionalised zeolite PPSU MMMs using lignosulfonate as a model foulant}

2.6.1. Lignin filtration. The filtration and fouling studies were carried out using lignosulfonate $\left(1 \mathrm{~g} \mathrm{~L}^{-1}\right)$ dissolved in distilled water. The performance evaluation in terms of the filtration of model pollutant using a UF set-up with subsequent cycles of backwashing and chemical cleaning was performed to investigate the influence of nanomaterials on PPSU MMMs. The feed solution was subjected to filtration with cycles of hydraulic backwashing and chemical cleaning employing the synthesized MMMs. The permeate flux of lignin feed solution $\left(J_{\mathrm{s}}\right)$ was determined and the corresponding water fluxes due to backwashing $\left(J_{\mathrm{bw}}\right)$ and chemical cleaning $\left(J_{\mathrm{cc}}\right)$ were measured. The rejection efficiency owing to lignin filtration was determined with the help of analysing the permeate lignin concentration using a UV-visible spectrophotometer at a wavelength of $435 \mathrm{~nm}$. The \% rejection of lignin with respect to each synthesized MMM was found and compared with virgin PPSU.

\subsubsection{Membrane fouling analysis}

2.6.2.1. Flux recovery ratio. The anti-fouling property of the membranes can be demonstrated by the flux recovery ratio (FRR), as it determines the volume of permeate flux that can be recovered after repeated cycles of filtration. The FRR was estimated to compare the fouling resistance ability of virgin polymeric membranes with PPSU MMMs. The FRR is the ratio between initial pure-water flux $\left(J_{\mathrm{w} 1}\right)$ and the pure-water flux $\left(J_{\mathrm{w} 2}\right)$ found after lignin filtration. After $2 \mathrm{~h}$ of lignin filtration, the membranes were backwashed with pure water for $60 \mathrm{~min}$ and the pure water flux $\left(J_{\mathrm{w} 2}\right)$ was found using eqn (5). The following eqn (6) was then used to calculate FRR (\%). A higher FRR will imply a better anti-fouling property of the membrane. 


$$
\operatorname{FRR}(\%)=\frac{J_{\mathrm{w} 2}}{J_{\mathrm{w} 1}} \times 100
$$

2.6.2.2. Reversible and irreversible fouling studies. The fouling analysis was evaluated by the degree of fouling, which includes the flux loss due to reversible and irreversible fouling after effluent treatment. In the case of filtration of industrial effluent, the total fouling $R_{\mathrm{t}}$ is represented by the sum of two types of fouling, such as reversible and irreversible fouling The reversible fouling ratio $\left(R_{\mathrm{r}}\right)$ could be eliminated by hydraulic cleaning using the eqn (7):

$$
R_{\mathrm{r}}(\%)=\frac{J_{\mathrm{bw}}-J_{\mathrm{f}}}{J_{\mathrm{bw}}} \times 100
$$

The irreversible fouling ratio $\left(R_{\mathrm{ir}}\right)$ eliminated with chemical cleaning was determined using eqn (8):

$$
R_{\mathrm{ir}}(\%)=\frac{J_{\mathrm{bw}}-J_{\mathrm{cc}}}{J_{\mathrm{bw}}} \times 100
$$

In these experiments, the operational conditions for the filtration steps were a constant transmembrane pressure (TMP) of $345 \mathrm{kPa}$. Removal of the remaining reversible fouling was achieved through a $5 \mathrm{~min}$ relaxation step and 3 cycles were applied to ensure an adequate measurement of the irreversible fouling propensity. In each relaxation step (interval), part of the permeability is recovered as the reversible fouling is removed.

2.6.3. Fouling resistances. From the flux decline with respect to time, the total resistances $\left(R_{\mathrm{t}}\right)$ as given in eqn (7) comprise the intrinsic membrane resistance $\left(R_{\mathrm{m}}\right)$, resistance due to concentration polarisation $\left(R_{\mathrm{cp}}\right)$ and resistance due to fouling $\left(R_{\mathrm{f}}\right)$ caused by cake layer resistance $\left(R_{\mathrm{c}}\right)$ and adsorption $\left(R_{\mathrm{a}}\right)$, respectively, of synthesized MMMs.

$$
\begin{gathered}
J=\frac{\Delta P}{\mu R_{\mathrm{t}}} \\
R_{\mathrm{t}}=R_{\mathrm{m}}+R_{\mathrm{cp}}+R_{\mathrm{f}} \\
R_{\mathrm{f}}=R_{\mathrm{c}}+R_{\mathrm{a}}
\end{gathered}
$$

The resistances $R_{\mathrm{cp}}, R_{\mathrm{c}}$ and $R_{\mathrm{a}}$ were determined from the permeate flux of lignin, and the pure water flux after hydraulic backwashing and chemical cleaning, respectively, as shown in eqn (10)-(12):

$$
\begin{gathered}
R_{\mathrm{cp}}=\frac{\Delta P}{\mu J_{\mathrm{cc}}}-R_{\mathrm{m}} \\
R_{\mathrm{c}}=\frac{\Delta P}{\mu J_{\mathrm{bw}}}-R_{\mathrm{m}}-R_{\mathrm{cp}} \\
R_{\mathrm{a}}=\frac{\Delta P}{\mu J_{\mathrm{s}}}-R_{\mathrm{m}}-R_{\mathrm{cp}}-R_{\mathrm{c}}
\end{gathered}
$$

where $J_{\mathrm{w}}$ is the initial water flux, $J_{\mathrm{bw}}$ is the water flux obtained after removing the cake layer by backwashing for $10 \mathrm{~min}, J_{\text {cc }}$ is the water flux after $10 \mathrm{~min}$ of chemical cleaning with a $0.1 \mathrm{M}$ $\mathrm{HCl}$ solution and $J_{\mathrm{s}}$ is the flux of lignin at the end of filtration.

\section{Results and discussion}

\subsection{XRD analysis}

Fig. 1 displays the XRD patterns of ZSM-5, Cu-ZSM-5 and FeZSM-5 and they match very well with the standard data of ZSM-5 from JCPDS no: 00-045-0437. ${ }^{35}$ The particle size of pristine ZSM-5 is found to be smaller than that for the metal exchanged zeolites such as Fe-ZSM-5 and Cu-ZSM-2. The diffraction intensity corresponding to $\mathrm{Fe}$ and $\mathrm{Cu}$ is observed at $45.4^{\circ}$ and $30.3^{\circ}$, respectively, with a lower intensity owing to a minimal amount being added to the pristine ZSM-5 zeolite. The interaction of metals with ZSM-5 was confirmed by the sharpness of intensity at $2 \theta$ of $23.15^{\circ}$ and $24.5^{\circ}$ corresponding to the $\left(\begin{array}{lll}2 & 2 & 0\end{array}\right)$ and $\left(\begin{array}{lll}3 & 1 & 1\end{array}\right)$ planes of a cubic crystal system.

The XRD diffractograms of PPSU and PP/Ze MMMs were recorded as shown in Fig. 2(a). The presence of the zeolite was confirmed by the intense peaks at $2 \theta=23.2$ and $23.5^{\circ}$ in all PP/Ze MMMs, among which the PPSU MMMs containing 1 wt\% of zeolite showed a higher peak intensity, indicating the presence of a larger amount of zeolite component in the MMMs. The sharpening of the peak corresponding to virgin PPSU at $\sim 19.5^{\circ} 2 \theta$ in all $\mathrm{PP} / \mathrm{Ze}$ MMMs indicates that the zeolitic particles had rendered crystallinity due to complete miscibility with PPSU. The functionalised zeolite with $\mathrm{Fe}^{3+}$ and $\mathrm{Cu}^{2+}$ has been confirmed to have been incorporated in PPSU, as observed from the XRD patterns of PP/Fe-Ze and PP/ $\mathrm{Cu}-\mathrm{Ze} \mathrm{MMMs}$, respectively. In the case of $\mathrm{PP} / \mathrm{Cu}-\mathrm{Ze}-4 \mathrm{MMM}$, the sharpening of the peaks confirms the crystallinity offered by the good miscibility of Cu-ZSM-5. Similar sharpened peaks observed for Fe-ZSM-5 incorporated PPSU MMMs confirms the miscibility in the casting solution. In addition, for $\mathrm{PP} / \mathrm{Fe}-$ Ze- 4 MMM, the peaks at $2 \theta$ angles of $17.4^{\circ}$ and $14.8^{\circ}$ represented the occurrence of Fe (Fig. 2(b)). However, there was no sharpening of the peaks when compared to virgin PPSU, which further implies the loss of complete miscibility between PPSU and Fe-ZSM-5, especially at higher fractions. This result implies the effect of phase separation that occurred at the stage of preparation of casting solution of PP/ Fe-Ze MMMs. ${ }^{36}$

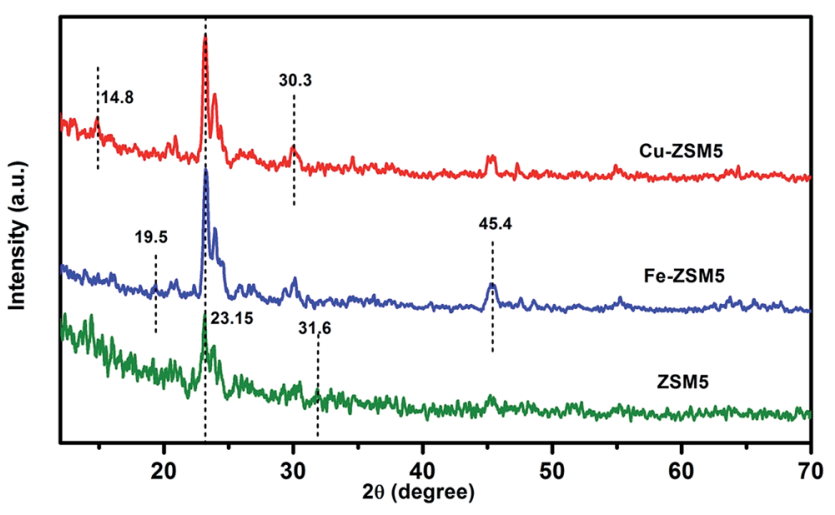

Fig. 1 XRD pattern of ZSM-5 and functionalised ZSM-5. 


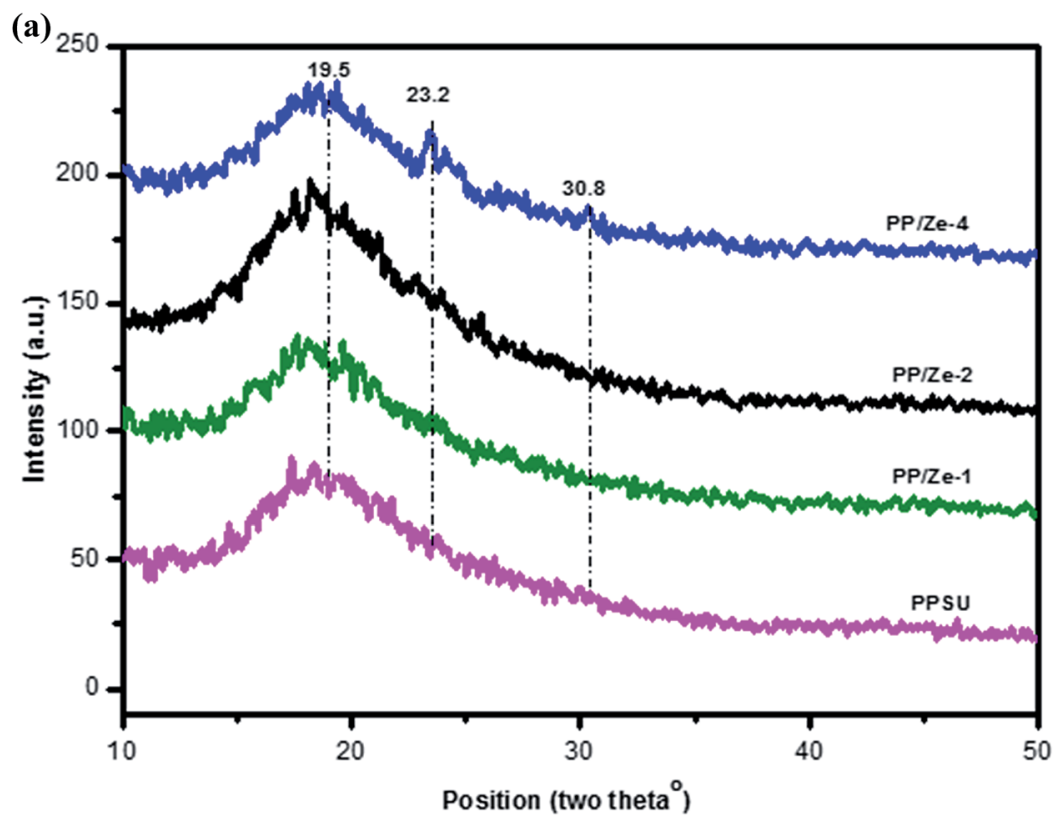

(b)

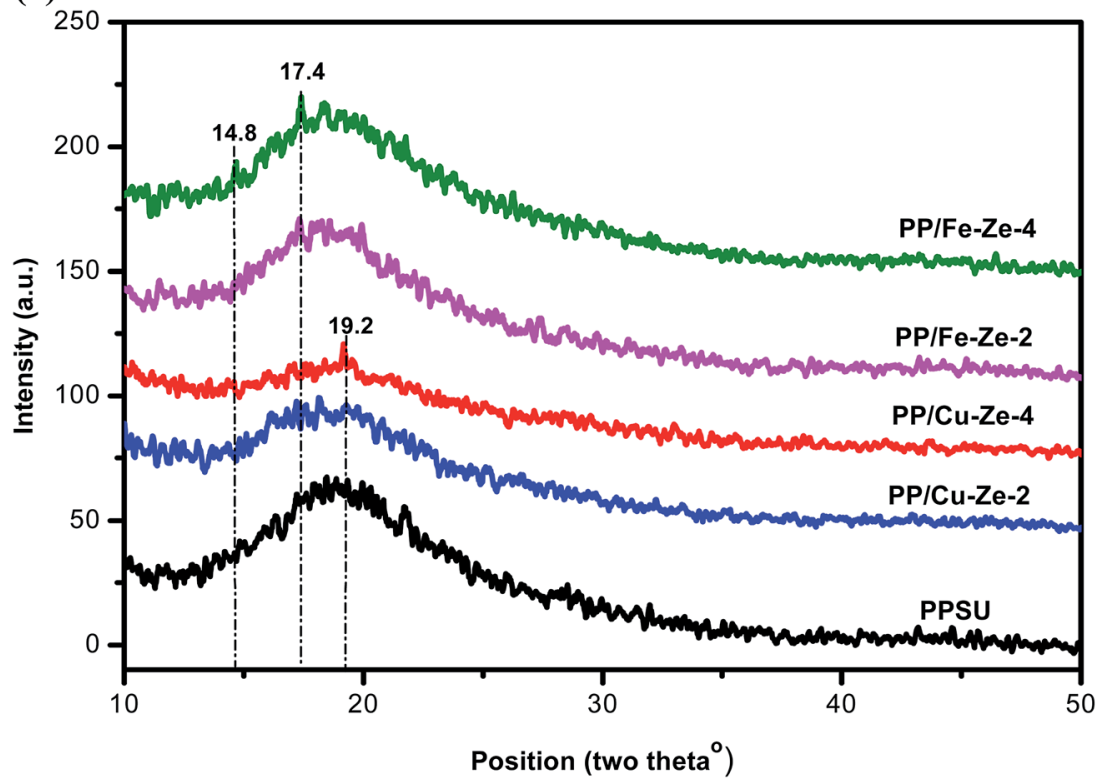

Fig. 2 (a) XRD characterisation of PP/Ze MMMs (b) XRD characterisation of PP/Fe-Ze and PP/Cu-Ze MMMs.

3.2. Particle size analysis and zeta sizer of ZSM-5, Cu-ZSM-5, Fe-ZSM-5 nanomaterials

The particle size and crystal size of ZSM-5, Cu-ZSM-5, Fe-ZSM-5 were analysed using a particle size analyzer and FWHM of XRD calculation and are displayed in Table 3 . The zeta potential and particle size of zeolite and functionalised zeolite have been correlated with their influence towards improving the properties of synthesized MMMs. From the results, it was found that among all the nanomaterials, ZSM-5 has the lowest particle size of $63.78 \mathrm{~nm}$. The pristine ZSM-5 showed a smaller particle size of $63.78 \mathrm{~nm}$ than the functionalized one and the functionalised inorganic nanomaterials such as ZSM-5, Cu-ZSM-5, and FeZSM-5 also showed negative potentials of more than $25 \mathrm{mV}$, which further ensured their good stability. The increasing zeta potential would offer a better degree of dispersion in the polymeric matrix in the order of ZSM-5 > Cu-ZSM-5 > Fe-ZSM-5. The particle size and zeta potential of the synthesized inorganic nanomaterials helped to bring about a stable homogenous solution with the PPSU polymeric matrix.

\subsection{Surface and cross-section morphology of zeolite and} functionalised zeolite incorporated PPSU MMMs

Fig. 3 shows that the PPSU modified with ZSM-5 exhibited a porous surface structure in $\mathrm{PP} / \mathrm{Ze} \mathrm{MMM}$. The increase in pore volume on the surface offers the higher water flux of $\mathrm{PP} / \mathrm{Ze}$ MMMs. From the images, it could be observed that for the 
Table 3 Physical properties of zeolite and functionalised zeolite

\begin{tabular}{|c|c|c|c|c|c|}
\hline \multirow[b]{2}{*}{ Nanomaterials } & \multirow[b]{2}{*}{ Diffraction angle $\left(^{\circ}\right)$} & \multirow[b]{2}{*}{ FWHM $\left(^{\circ}\right)$} & \multicolumn{2}{|l|}{ Particle size (nm) } & \multirow[b]{2}{*}{ Zeta potential $(\mathrm{mV})$} \\
\hline & & & Crystal size by XRD & Particle size analyser & \\
\hline ZSM-5 & 23.23 & 1.4964 & 61.40 & 63.78 & -57.2 \\
\hline Cu-ZSM-5 & 23.17 & 1.5245 & 65.30 & 68.71 & -45.9 \\
\hline Fe-ZSM-5 & 23.32 & 1.4597 & 63.25 & 63.85 & -38.8 \\
\hline
\end{tabular}
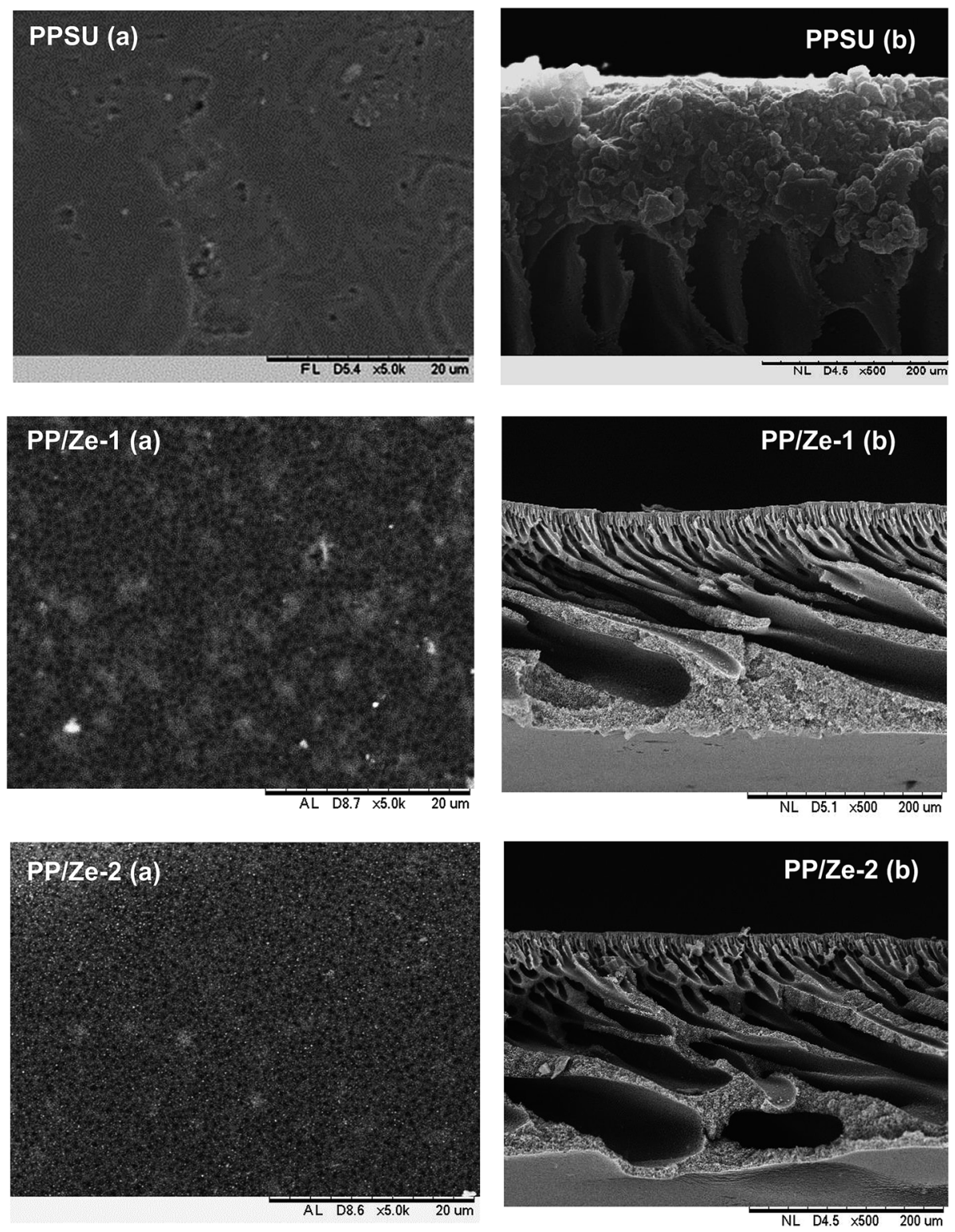

Fig. 3 Surface (a) and cross-section (b) morphology of PP/Ze MMMs.

addition 0.5 wt $\%$ of ZSM-5, uniform dispersion in $\mathrm{PP} / \mathrm{Ze}-2$ MMM was evident. The addition of different concentrations of zeolite nanoparticles resulted in the growth of a membrane sublayer porosity. ${ }^{37}$ Moreover, sub-layer macro-voids have grown by increasing the amount of zeolite in the membrane matrix. On the addition of zeolite, the macro voids in the sub-layer got elongated with the increasing pore volume. However, increasing the zeolite concentration from 0.5 to $1 \mathrm{wt} \%$ delayed the phase inversion phenomenon and hence there occurred the elongation of finger pores as observed for PP/Ze-4 MMM. As suggested by previous studies, ${ }^{\mathbf{1 , 3 8}}$ particle agglomeration is due to sedimentation or migration to the surface. 
The surface and cross-sectional morphology of $\mathrm{Cu}$-zeolite incorporated PPSU is shown in Fig. 4. The minimum agglomeration in the membrane can be attributed to the excellent compatibility between PPSU and small sizes of zeolitic particles of Cu-ZSM-5, and the good dispersion of nano-sized particles in NMP offered a macrovoidal morphology for $\mathrm{PP} / \mathrm{Cu}-\mathrm{Ze} \mathrm{MMMs}$. A significantly more porous structure for the MMM is observed with an increase in loading to $0.5 \mathrm{wt} \%$. The blended $\mathrm{PP} / \mathrm{Cu}-\mathrm{Ze}$ MMMs have also proven to be effective in suppressing swelling as there was an intensive chain rigidification. Thus, Cu-ZSM-5 particles may rigidify PPSU chains and restrict the swelling of the polymeric phase. As a result, a better rejection ability is expected during filtration and treatment studies using $\mathrm{PP} / \mathrm{Cu}-$ Ze MMMs. Fig. 5 shows the SEM EDX spectra of a $0.25 \mathrm{wt} \% \mathrm{Cu}-$ ZSM-5 mixed PPSU membrane. It was observed that copper $(\mathrm{Cu})$, sodium $(\mathrm{Na})$, aluminium $(\mathrm{Al})$ and silicon $(\mathrm{Si})$ elements were present on the membrane surface. The EDX analysis demonstrated that the $\mathrm{Cu}$ particles on the modified PPSU membranes were zeolite nanoparticles, which had a homogeneous dispersion within the membrane surface.

In the case of $\mathrm{PP} / \mathrm{Fe}-\mathrm{Ze}$ MMMs, as shown in Fig. 6, the presence of Fe-ZSM-5 particles occupied the space in polymer and zeolite segments, forming finger-like obstructed pores in the bottom layer. The blended PP/Fe-Ze MMMs proved to be effective in suppressing the macro-voidal formation, as there was expected to be an intensive chain rigidification due to the functionalization of zeolite with Fe. Thus, Fe-zeolite particles may rigidify PPSU chains and thus restrict the swelling of the polymeric phase in $\mathrm{PP} / \mathrm{Fe}-\mathrm{Ze}$ MMMs. However, the increasing ZSM-5 concentration caused agglomeration, leading to the occurrence of non-selective voids in the interface of the ZSM-5 and PPSU matrix. The SEM-EDX analysis of the particle distribution on 0.25 wt $\%$ of Fe-ZSM- 5 particles in PP/Fe-Ze MMMs surface is shown in Fig. 7. The profiles are the line scan spectra of the element $\mathrm{Fe}$ on the major component of the zeolite. The SEM-EDX results confirmed that Fe elements with the surface
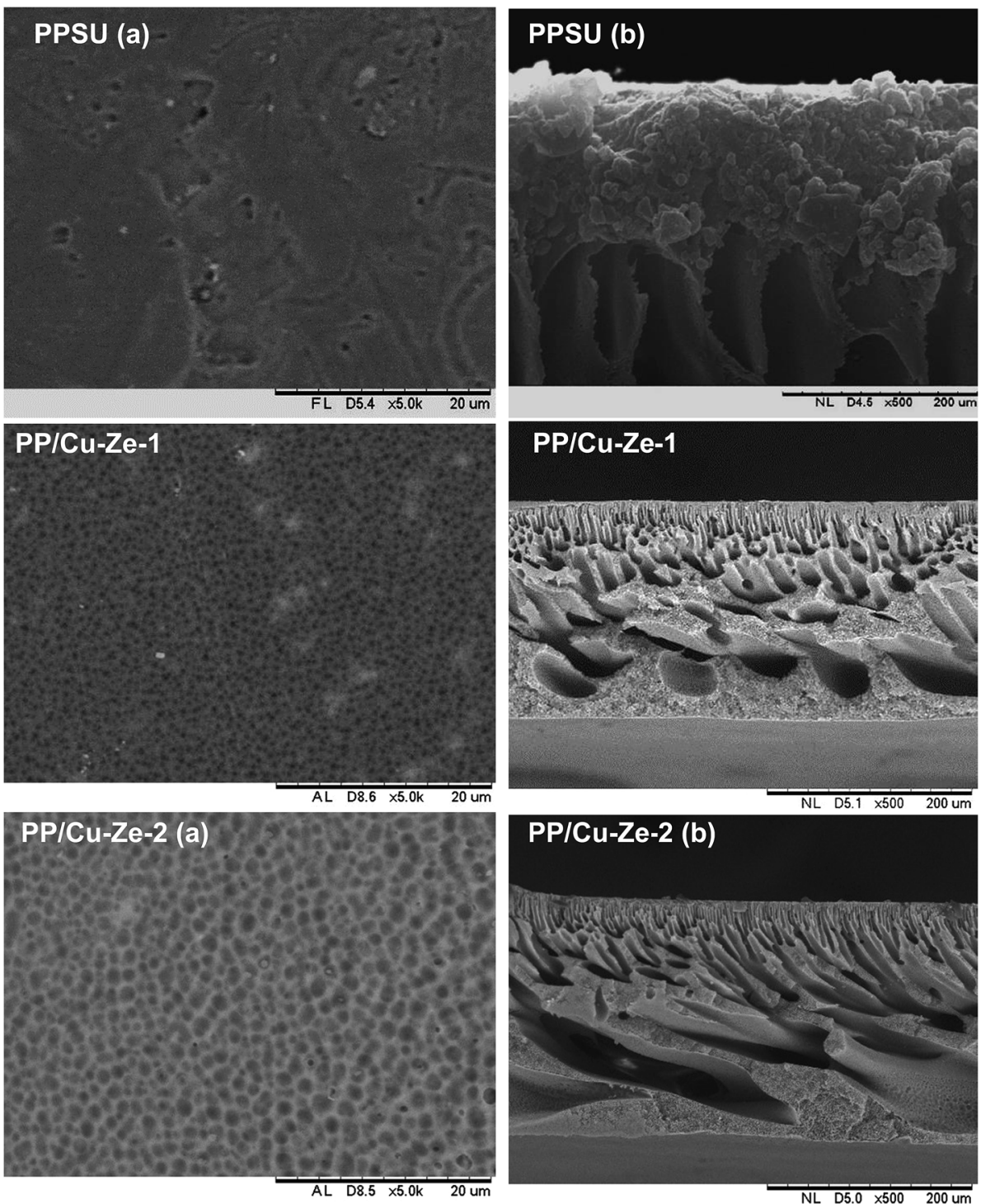

Fig. 4 Surface (a) and cross-section (b) morphology of PP/Cu-Ze MMMs. 

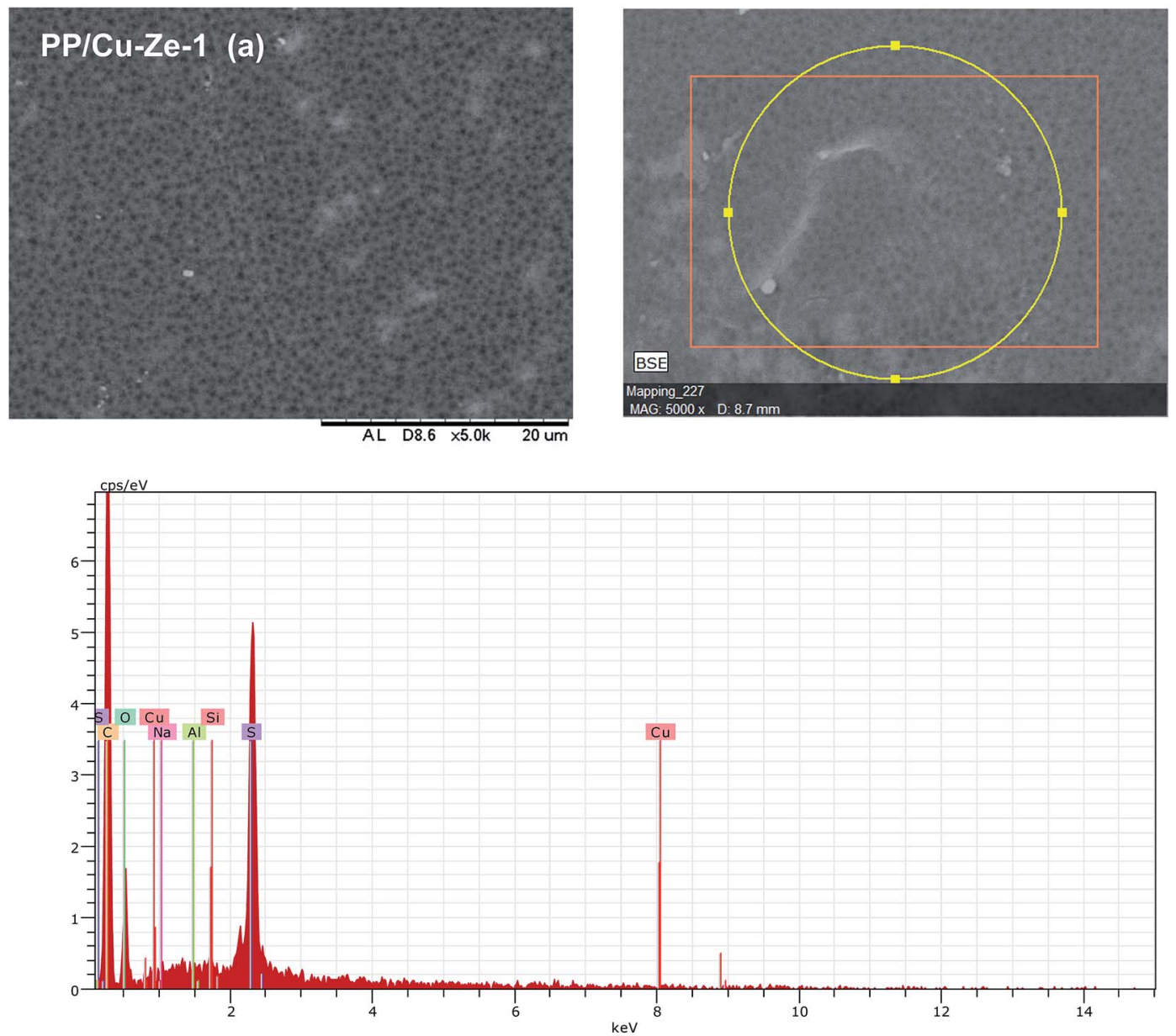

Fig. 5 SEM-EDX line scanning spectra for the surface of the 0.25 wt $\%$ of Cu-ZSM- 5 on PPSU MMMs.

composition ( $\mathrm{Na}, \mathrm{Al}, \mathrm{Si}, \mathrm{O}, \mathrm{C}$ elements) were incorporated and distributed on the surface of the PPSU membrane.

\subsection{Roughness behaviour of zeolite and functionalised zeolite incorporated PPSU MMMs}

The surface topography images of virgin PPSU were compared with $\mathrm{PP} / \mathrm{Ze}$ (Fig. 8), PP/Cu-Ze and PP/Fe-Ze MMMs as shown in Fig. 9. From Fig. 8, the surface roughness of PP/Ze-2 MMM increased owing to the addition of $0.5 \mathrm{wt} \%$ of ZSM-5 (Table 4). The peaks and valleys represented by ups and downs indicated higher surface roughness. The increase in the membrane surface roughness by adding zeolite nanoparticles might be due to the presence of ZSM-5 on the membrane surface, which subsequently increases the surface pore size. ${ }^{37}$ As the optimum loading of zeolitic moieties tends to create a preferential interface difference between the organic/inorganic phases, the roughness parameters of $\mathrm{PP} / \mathrm{Ze}$ MMMs were observed to be higher than in virgin PPSU membranes. The reduction in mean surface pore size and permeability also correlates well with the surface roughness properties. The decrease in roughness parameters owing to increasing the ZSM-5 addition to $1 \mathrm{wt} \%$ has been depicted in the three dimensional AFM images shown in Fig. 8.
The surface topography results of PP/Fe-Ze MMMs complement the morphological characteristics as observed in SEM images (Fig. 6). The images shown in Fig. 9 implied that Fe functional groups have interacted among themselves and with the zeolite which has conferred the surface with no significant up and down peaks. This also further reinforces the migration of Fe to the bottom layer of the PP/Fe-Ze MMMs, as observed in the SEM morphology in Fig. 6. In this regard, the $R_{\mathrm{a}}$ value has improved, being slightly higher than that for PPSU of about $18.52 \mathrm{~nm}$ for PP/Fe-Ze-1 MMM, as mentioned in Table 4. As roughness parameters validate the dispersion of incorporated nanoparticles, the minimal addition of $0.5 \mathrm{wt} \%$ of Fe-ZSM- 5 has ensured better dispersity compared to other loadings.

\subsection{Membrane surface charge properties of zeolite and functionalised zeolite incorporated PPSU MMMs}

The values of the zeta potential measurements for surface charge properties of MMMs are presented in Table 4. The virgin PPSU membrane shows a zeta potential of $-36.8 \mathrm{mV}$ at $\mathrm{pH} 7$ without modifications. As shown in Table 3, the zeta potential of ZSM-5 is $-57.2 \mathrm{mV}$ at $\mathrm{pH}$ 7. However, compared to the virgin PPSU membrane, the ZSM-5 is slightly more acidic and there are small amounts of negatively charged functional groups present 

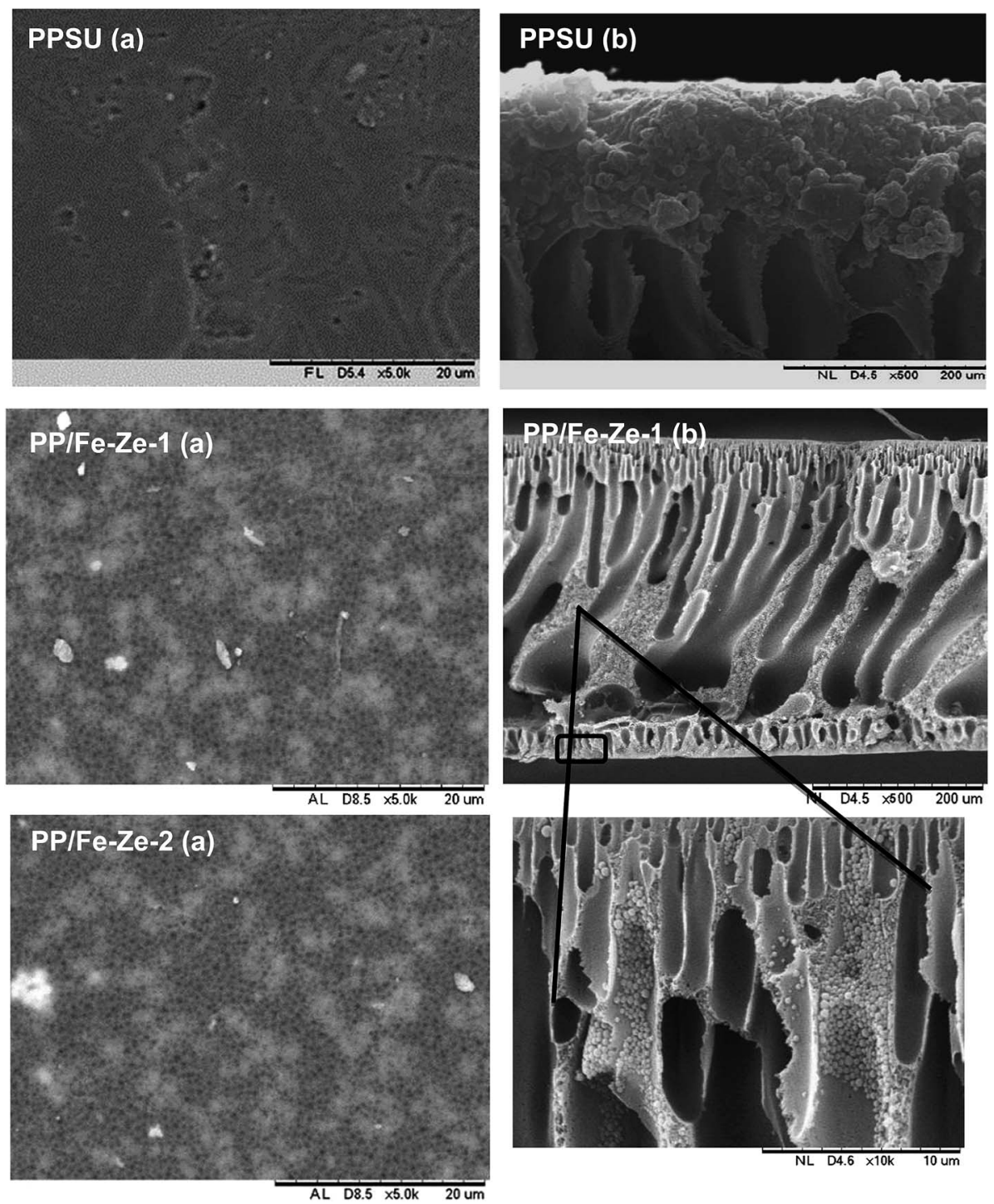

Fig. 6 Surface (a) and cross-section (b) morphology of PP/Fe-Ze MMMs.

on the membrane surface for $0.25,0.5,0.75$ and $1 \%$ in PPSU. Nevertheless, when Cu-ZSM-5 and Fe-ZSM-5 were added to the PPSU membrane it became clear that negatively charged groups were incorporated into the membrane surface by the increasing value of the zeta potential $(-42.5 \mathrm{mV}$ and $-44.2 \mathrm{mV})$. Hence, a modification with ZSM-5, Cu-ZSM-5 and Fe-ZSM-5 was considered and the modified PPSU membrane has a highly negative zeta potential at $\mathrm{pH} 7$, which confirms the introduction of a trivalent atom, such as aluminium, in tetrahedral coordination in the zeolite framework creating a negative network charge $^{39}$ in the presence of $\mathrm{Cu}$ and Fe functional metals.

\subsection{Hydrophilicity of zeolite and functionalised zeolite incorporated PPSU MMMs}

The chemical structure of a zeolite containing numerous oxygen (-O) bonding has made it hydrophilic by absorbing water molecules to form hydroxyl bonding. The zeolite present on the surface of $\mathrm{PP} / \mathrm{Ze}$ MMMs helped to reduce hydrophobicity, as there was a decrease in contact angle to $73.5^{\circ}$ on adding $0.5 \mathrm{wt} \%$ of zeolite, as shown in Table 4 . The metal functionalities have caused the ZSM-5 to rigidify the membrane surface which is also the reason for the decreased pore size of $\mathrm{PP} / \mathrm{Fe}-\mathrm{Ze}$ and $\mathrm{PP} /$ $\mathrm{Cu}-\mathrm{Ze}$ MMMs. The contact angle of PP/Fe-Ze MMMs has also reduced to the minimum of $76.1^{\circ}$ owing to the minimal addition of $0.25 \mathrm{wt} \%$, whereas for PPSU MMMs containing greater than $0.25 \mathrm{wt} \%$ the contact angle showed an increasing trend, suggesting the hydrophobic nature of the Fe-zeolite. In the case of the Fe-zeolite containing PPSU MMMs, the pore size becomes very much less at about $10 \mathrm{~nm}$ due to the blocking by Fe particles present in Fe-ZSM-5.

\subsection{Performance evaluation of zeolite and functionalised zeolite incorporated PPSU MMMs}

3.7.1. Effect of ZSM-5 on pure water flux. The PPSU modification using ZSM-5 has improved the pure water flux from 14.5 $\mathrm{L} \mathrm{m}^{-2} \mathrm{~h}^{-1}$ to $44.9 \mathrm{~L} \mathrm{~m}^{-2} \mathrm{~h}^{-1}$ and $62 \mathrm{~L} \mathrm{~m}^{-2} \mathrm{~h}^{-1}$ owing to the 

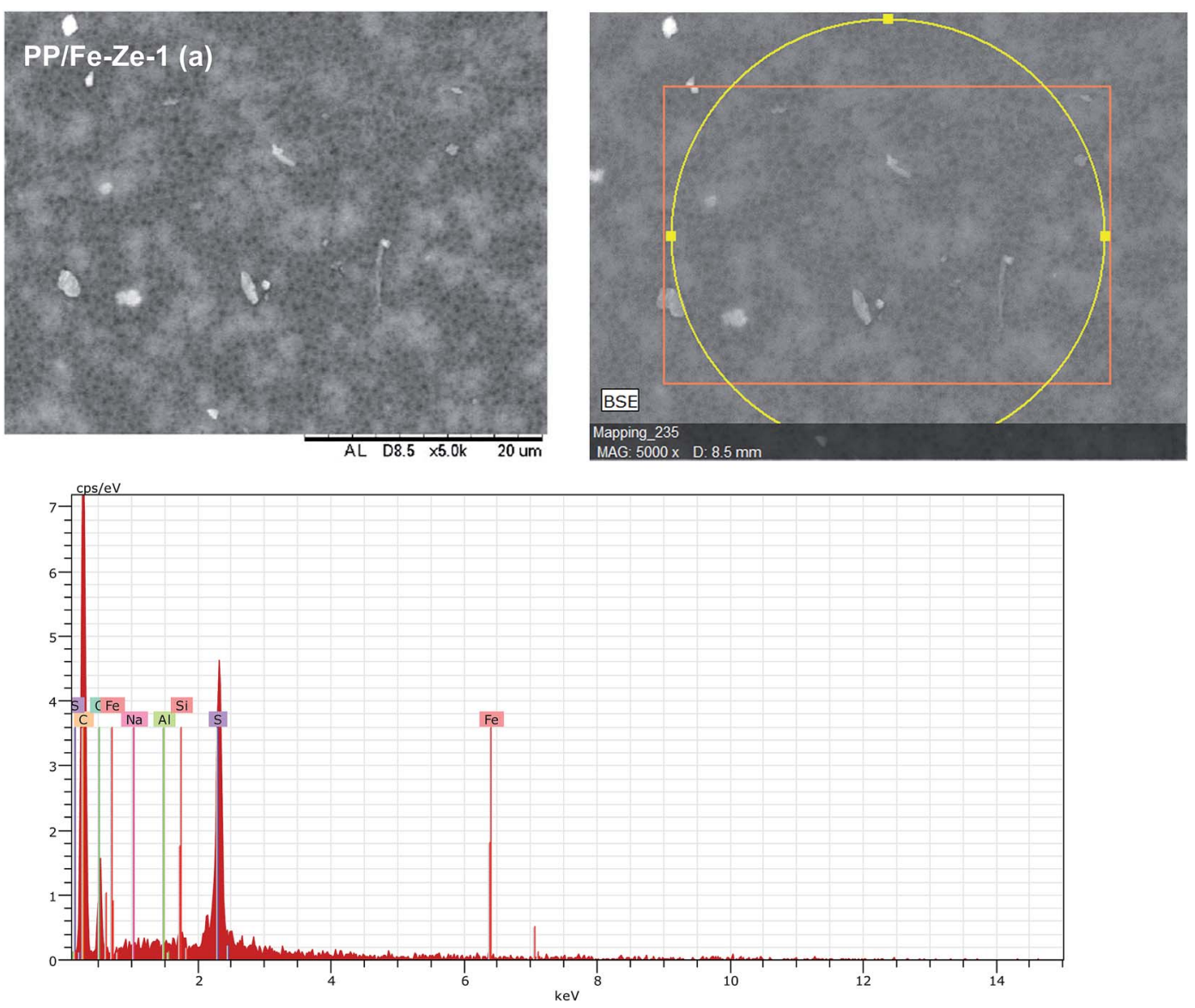

Fig. 7 SEM-EDX line scanning spectra for the surface of the 0.25 wt $\%$ of Fe-ZSM- 5 on PPSU MMMs.

incorporation of 0.25 and 0.5 wt $\%$ of ZSM-5, respectively (Fig. 10). These results are attributed to the hydrophilicity and change in surface morphology of PP/Ze MMMs. The hydrophilicity, porosity and pore radius of PP/Ze MMMs increased when the enhanced permeate flux was observed for PP/Ze MMMs. However, with the addition of ZSM- 5 beyond $0.5 \mathrm{wt} \%$, the water flux was decreased when compared to the virgin PPSU. This confirmed the occurrence of interfacial defects and delayed demixing during the preparation of PP/Ze-3 and PP/Ze-4 MMMs. This is due to the increase in the ZSM- 5 concentration beyond $0.5 \mathrm{wt} \%$ which has led to such effects during the preparation of the doped casting solution of PP/Ze-3 and PP/Ze-4 MMMs.

MMMs have shown increasing flux in the range from $27 \%$ to $267 \%$ compared to pristine membranes, as reported in the literature. ${ }^{40,41}$ On incorporating zeolite, the above improvement in flux performance is impressive as there has been a rapid improvement of about 209.6 and a $327.5 \%$ increase in water flux over that of virgin PPSU MMMs. ZSM-5 are microporous and hydrophilic in nature and hence could enhance the water permeability of $\mathrm{PP} / \mathrm{Ze}$ MMMs. Considering this increase in the permeate flux of the PP/Ze MMMs, it can be deduced that the blending of ZSM-5 up to $0.5 \mathrm{wt} \%$ has increased the pore size in the membrane surface, whereas blending beyond $0.5 \mathrm{wt} \%$ of ZSM-5 resulted in a decrease in pore elongation due to a delay in phase separation which subsequently caused a decrease in pure water flux.
3.7.2. Effect of Cu-ZSM-5 and Fe-ZSM-5 in MMMs on pure water flux. In contrast to $\mathrm{PP} / \mathrm{Ze}$ MMMs, the effect of Cu-ZSM-5 has reduced the water flux. The optimum wt $\%$ concentration of 0.5 of Cu-ZSM- 5 has only improved the pure water flux to 19.5 $\mathrm{L} \mathrm{m}^{-2} \mathrm{~h}^{-1}$ (Fig. 10). The loading of Cu-ZSM-5 higher than $0.5 \mathrm{wt} \%$ started to reduce the water flux to less than the water flux of virgin PPSU. The decrease in flux compared to PP/Ze and PPSU is due to the higher contact angle values for PP/ $\mathrm{Cu}-\mathrm{Ze}$. The addition of Fe-ZSM-5 has affected the pure water flux to a maximum extent, as a water flux of around 1.25 to $0.85 \mathrm{~L} \mathrm{~m}^{-2} \mathrm{~h}^{-1}$ has been observed for all the different compositions of PP/Fe-Ze MMMs. From the morphology of PP/ $\mathrm{Fe}-\mathrm{Ze}$ MMMs itself, the separation of $\mathrm{Fe}^{2+}$ cations during the formation of asymmetric UF membranes was witnessed, which further obstructed the pore volume to a greater extent. This was the same for lower to higher concentrations of Fe-ZSM-5 in $\mathrm{PP} / \mathrm{Fe}-\mathrm{Ze}$ MMMs.

The higher contact angle values of both $\mathrm{PP} / \mathrm{Fe}-\mathrm{Ze}$ and $\mathrm{PP} /$ $\mathrm{Cu}-\mathrm{Ze}$ MMMs were most probably due to the presence of Fe and $\mathrm{Cu}$ particles with oxidation numbers 2 or 3 ; which were highly entrapped, thus inducing hydrophobicity in the membrane surfaces. The pore diameter was also reduced drastically due to the blending of this functionalised zeolite. However, in the case of metal exchanged zeolites such as Cu-ZSM-5 and Fe-ZSM-5 based PPSU MMMs the flux decreased. This suggests that the 


\section{PPSU}

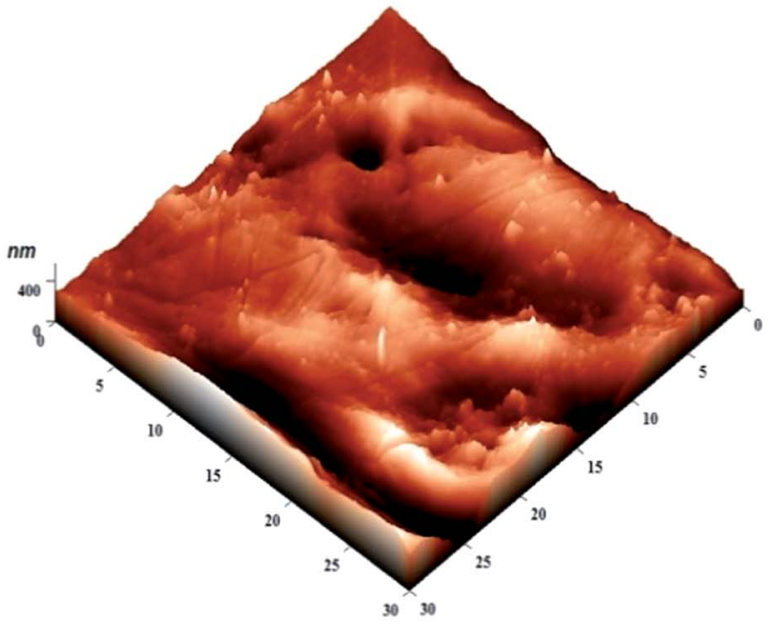

$\mu m \quad \mu m$

\section{PP/Ze-1 MMM}

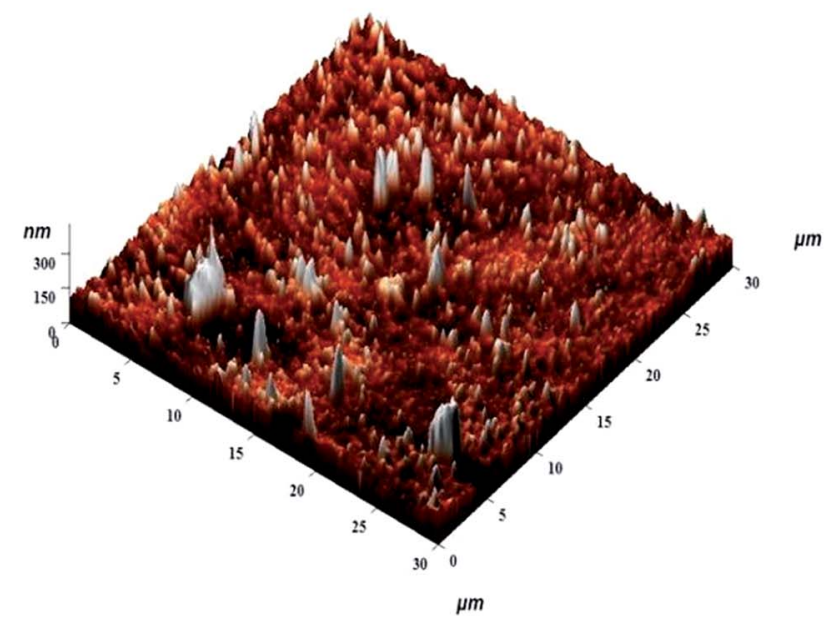

PP/Ze-4 MMM

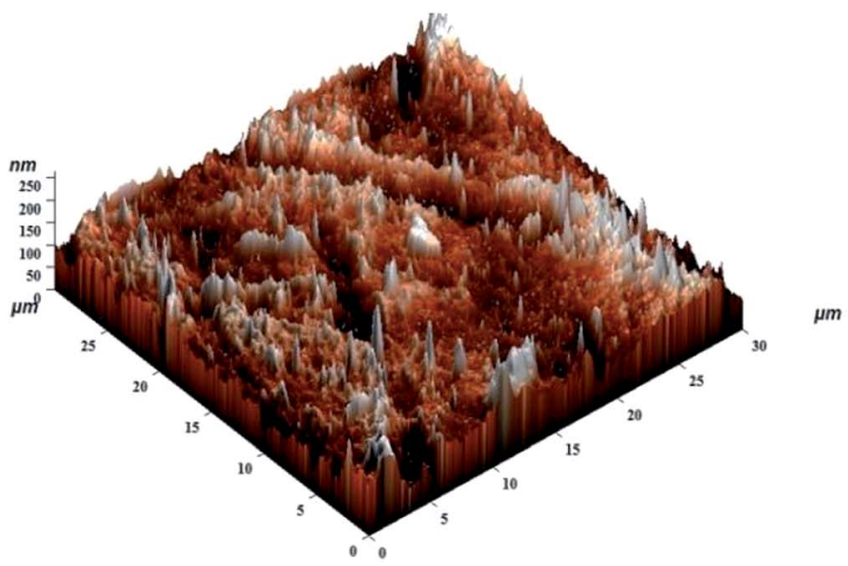

Fig. 8 Surface topography of PP/Ze MMMs.

metal associated zeolitic frameworks can act better as molecular sieves with a higher rejection efficiency.

3.7.3. Lignin rejection studies using zeolite and functionalised zeolite incorporated PPSU MMMs. Zeolite incorporation has caused the PPSU matrix to become loosened, thus increasing the permeating ability of $\mathrm{PP} / \mathrm{Ze}$ MMMs that consequently affected the lignin rejection\%. The highest lignin retention of about $85.2 \%$ was inferred for PPSU MMMs containing $0.5 \mathrm{wt} \%$ of ZSM-5 compared to the highest rejection efficiency of PPSU of $78.4 \%$ (Fig. 11). This 3D porous structure of ZSM-5 has also resulted in a profound effect on the enhanced flux compared to virgin PPSU. The rejection of lignin has also been evaluated using PP/Cu-Ze and PP/Fe-Ze MMMs, as shown in Fig. 12. It was evident that the incorporation of functionalised zeolite nanomaterials has led to a decrease in permeability with the trade-off of increased rejection\%. The maximum lignin rejection\% of 88.5 was obtained for $\mathrm{PP} / \mathrm{Cu}-\mathrm{Ze}-2 \mathrm{MMM}$. Therefore, the changes in lignin permeability with a loading of 0.25 to $0.5 \mathrm{wt} \%$ could be explained by taking into account a combination of two factors. The first factor means that physical (an asymmetric structure with a dense bottom layer) properties are responsible for a decrease in transport through the Cu-ZSM-5 particle like permeability. The second factor is the enhanced hydrophilic properties with the skin top layer which are responsible for good rejection and which increase the antifouling property of the membranes.

\subsection{Anti-fouling properties of zeolite and functionalised} zeolite incorporated PPSU MMMs

In order to determine the antibiofouling property and reproducibility of the membrane, four cycles of clean water and wastewater fouling experiments were performed for the PES and zeolite and functionalised zeolite incorporated PPSU MMMs. Fig. 13 proves that the observed flux behaviour of the PP/Ze MMMs is due to irreversible fouling which was higher owing to the adsorptive property of the ZSM-5 structures. The irreversible fouling resistance played a significant role in the case of 


\section{PPSU}

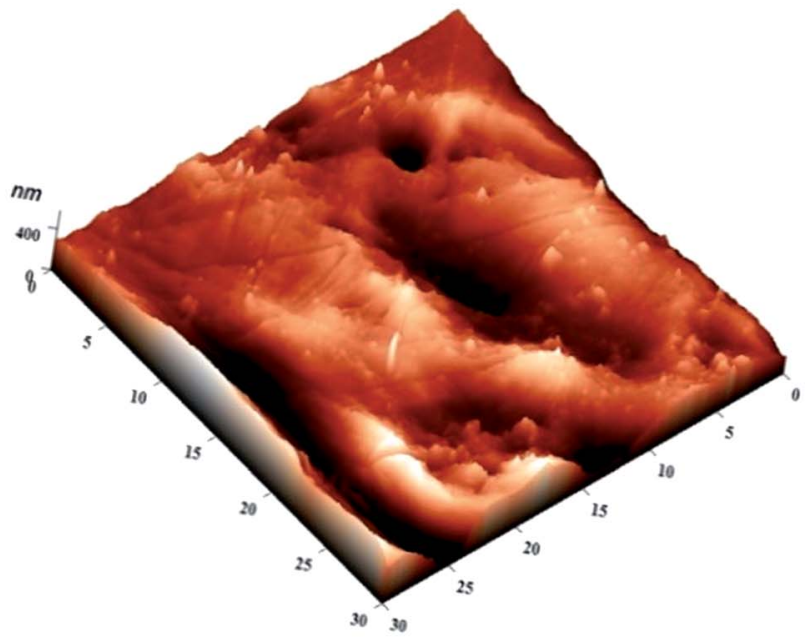

PP/Cu-Ze-4 MMM

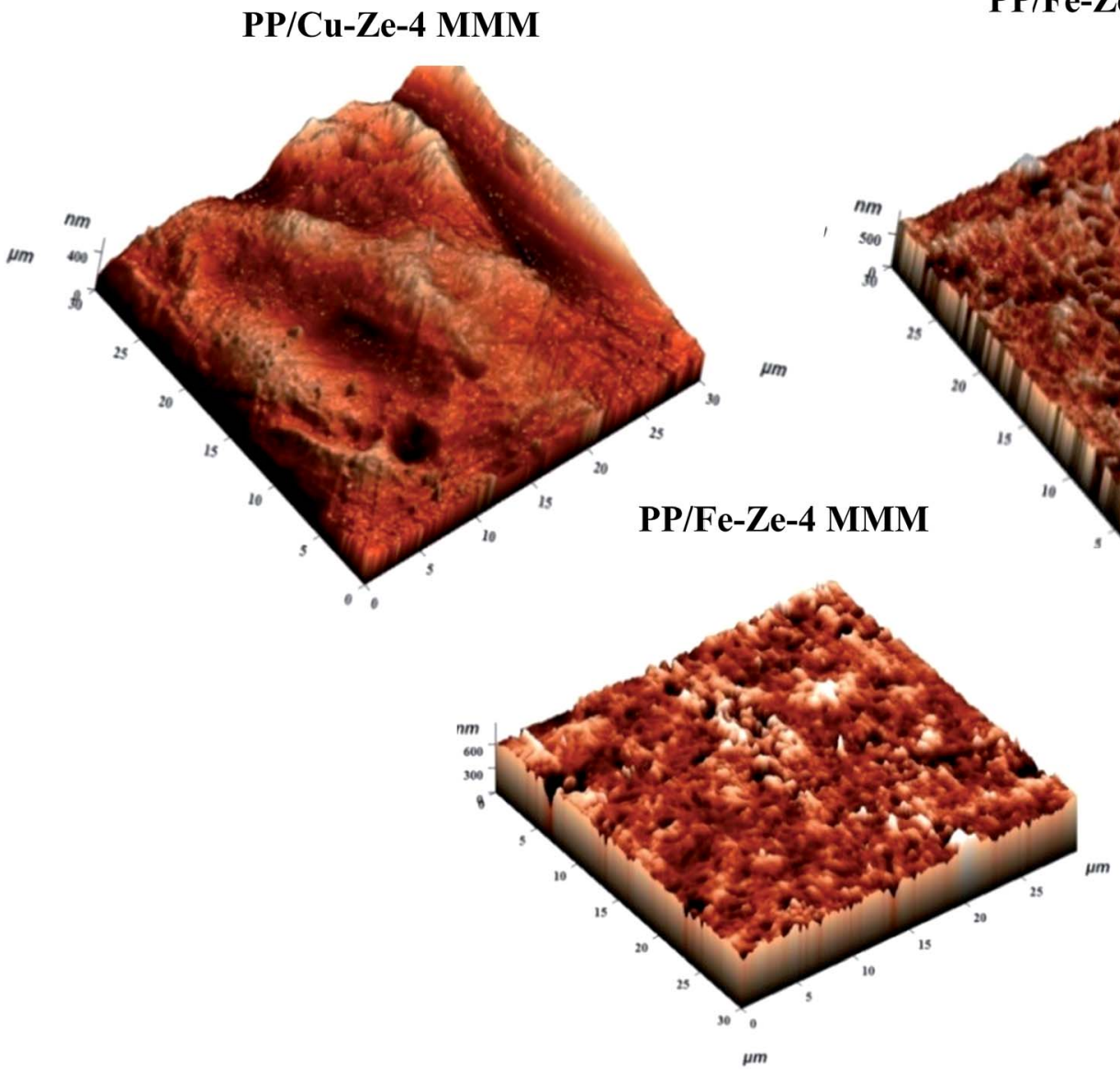

PP/Cu-Ze-1 MMM

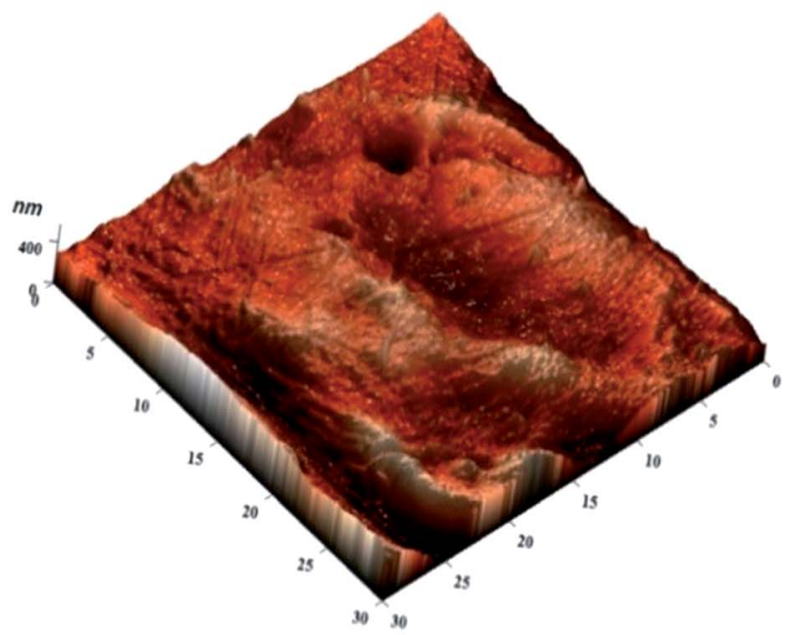

PP/Fe-Ze-1 MMM

Fig. 9 Surface topography of PP/Cu-Ze and PP/Fe-Ze MMMs.

PP/Ze MMMs, as there exists a remarkable flux enhancement after chemical cleaning when compared to virgin PPSU. This is due to the adsorptive nature of the ZSM-5 moieties present in PPSU. ZSM-5 have permanent negative charges as well as an interconnection of channels and cages running through their secondary framework structure, and they are also efficient adsorbents of pollutants and heavy metals. ${ }^{26}$

The fouling ratios of PP/Ze MMMs along with their FRR\% are shown in Fig. 14. The FRR of the membranes increased considerably from $31 \%$ for the unmodified PES membrane to 
Table 4 Surface and pore characteristics of zeolite and functionalised zeolite PPSU MMMs

\begin{tabular}{|c|c|c|c|c|c|c|}
\hline \multirow[b]{2}{*}{ Membrane type } & \multirow{2}{*}{$\begin{array}{l}\text { Contact } \\
\text { angle }\left(^{\circ}\right)\end{array}$} & \multirow{2}{*}{$\begin{array}{l}\text { Surface energy } \\
\left(\mathrm{kJ} \mathrm{m}^{-2}\right)\end{array}$} & \multicolumn{2}{|c|}{ Surface roughness } & \multirow{2}{*}{$\begin{array}{l}\text { Pore size } \\
(\mathrm{nm})\end{array}$} & \multirow{2}{*}{$\begin{array}{l}\text { Zeta Potential } \\
(\mathrm{mV})\end{array}$} \\
\hline & & & $R_{\mathrm{a}}(\mathrm{nm})$ & $R_{\mathrm{rms}}(\mathrm{nm})$ & & \\
\hline PPSU & 84.2 & 80.15 & 10.42 & 16.40 & 30.4 & -36.8 \\
\hline PP/Ze-1 & 76.9 & 89.30 & 22.50 & 38.61 & 34.8 & -43.0 \\
\hline $\mathrm{PP} / \mathrm{Ze}-2$ & 73.5 & 93.47 & 25.74 & 41.52 & 39.4 & -48.3 \\
\hline $\mathrm{PP} / \mathrm{Ze}-3$ & 74.5 & 92.25 & 26.54 & 40.23 & 35.0 & - \\
\hline $\mathrm{PP} / \mathrm{Ze}-4$ & 74.6 & 92.13 & 20.85 & 34.21 & 20.6 & - \\
\hline $\mathrm{PP} / \mathrm{Cu}-\mathrm{Ze}-1$ & 79.4 & 86.20 & 23.50 & 41.00 & 17.0 & - \\
\hline $\mathrm{PP} / \mathrm{Cu}-\mathrm{Ze}-2$ & 75.3 & 91.30 & 27.00 & 42.33 & 20.6 & -43.5 \\
\hline $\mathrm{PP} / \mathrm{Fe}-\mathrm{Ze}-1$ & 76.1 & 90.28 & 18.52 & 22.42 & 10.0 & - \\
\hline $\mathrm{PP} / \mathrm{Fe}-\mathrm{Ze}-2$ & 79.6 & 85.9 & 15.42 & 20.43 & 11.2 & -44.2 \\
\hline
\end{tabular}

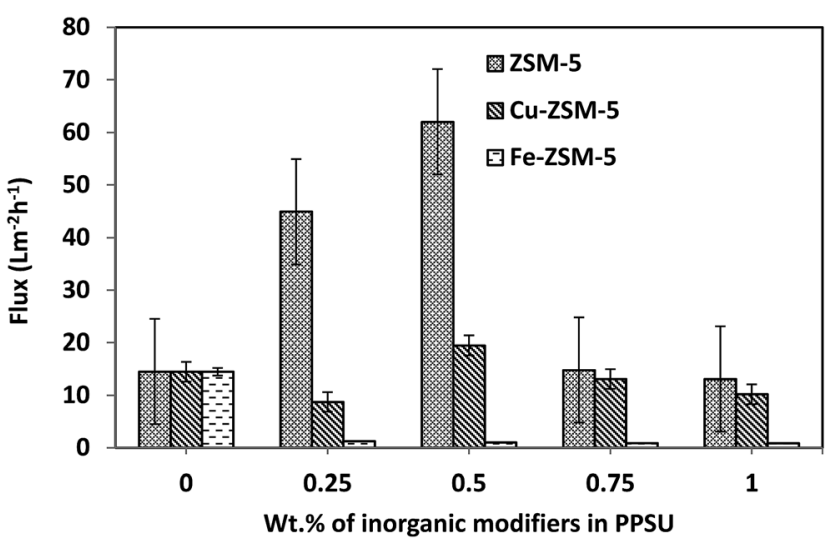

Fig. 10 Pure water flux of PPSU MMMs.

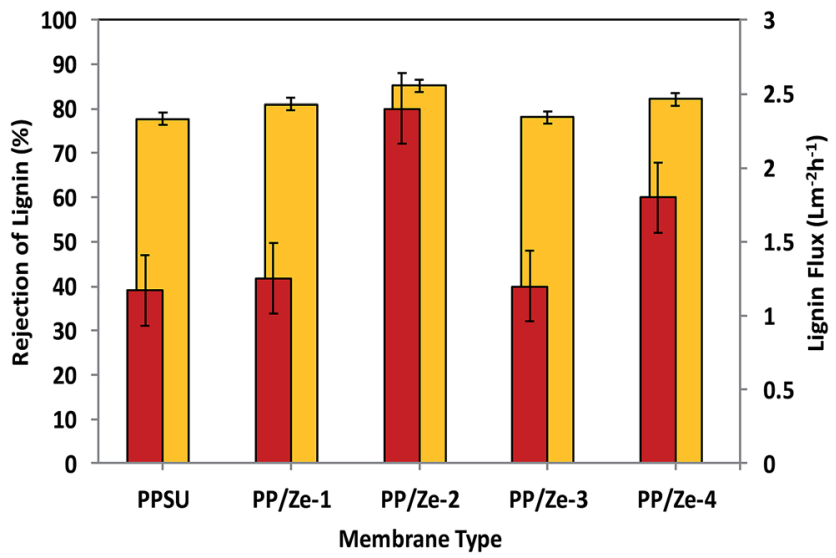

Fig. 11 Lignin filtration studies on PP/Ze MMMs.

$68.5 \%$ for the $0.5 \mathrm{wt} \%$ ZSM- 5 blended membrane. These results demonstrate that the ZSM-5 incorporated membranes show remarkable antifouling properties. Further, the FRR values of ZSM-5 incorporated membranes were improved, which confirmed that the surface properties of the membrane were modified.

From Table 5 it can be observed that among PP/Ze MMMs, the fouling resistance such as $R_{\mathrm{c}}$ and $R_{\mathrm{a}}$ was less by about 0.1 and $1.26 \times 10^{-6} \mathrm{~m}^{-1}$ for $\mathrm{PP} / \mathrm{Ze}-2 \mathrm{MMMs}$ which is attributable to the pore structure and surface properties of the membrane. The chemical cleaning has enabled the $\mathrm{PP} / \mathrm{Cu}-\mathrm{Ze}$ MMMs to recover the actual initial lignin flux to the maximum level compared to $\mathrm{PP} / \mathrm{Fe}-\mathrm{Ze}$ MMMs. For the resistance values of Cu-ZSM- 5 and FeZSM-5 incorporated PPSU MMMs, as shown in Table 5, the effect of Cu-ZSM- 5 could be observed in the decrease in irreversible fouling resistance to about $2.67 \times 10^{6} \mathrm{~m}^{-1}$ when compared to virgin PPSU with $11.24 \times 10^{6} \mathrm{~m}^{-1}$. However, on

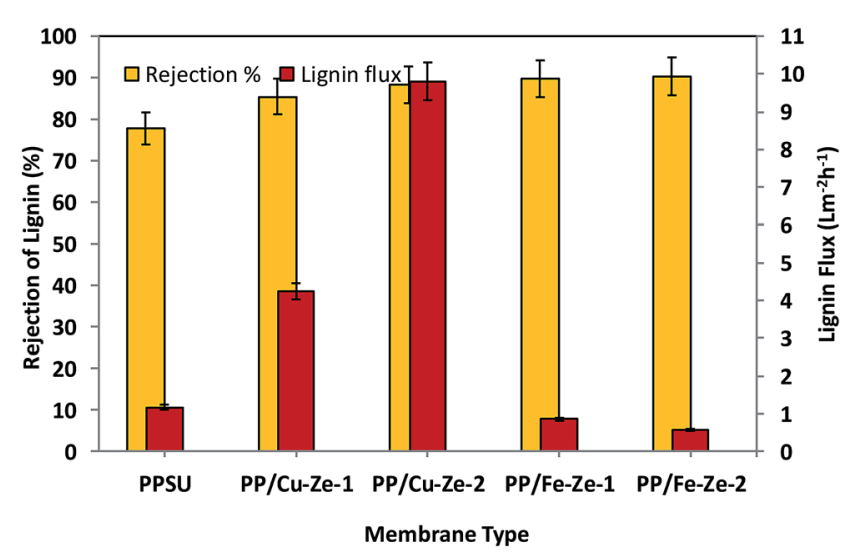

Fig. 12 Lignin filtration studies on PP/Cu-Ze and PE/Fe-Ze MMMs.

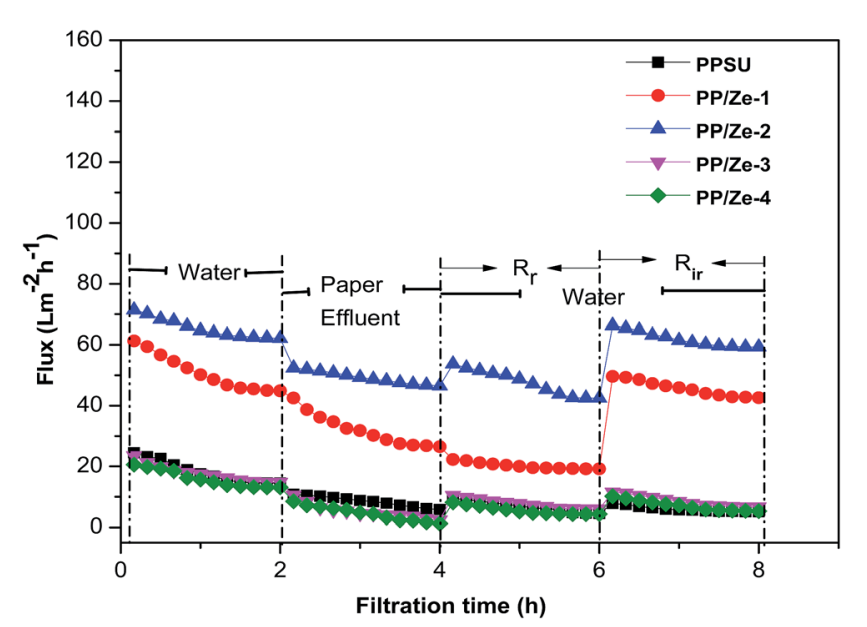

Fig. 13 Flux behaviour of PP/Ze MMMs during lignin filtration. 


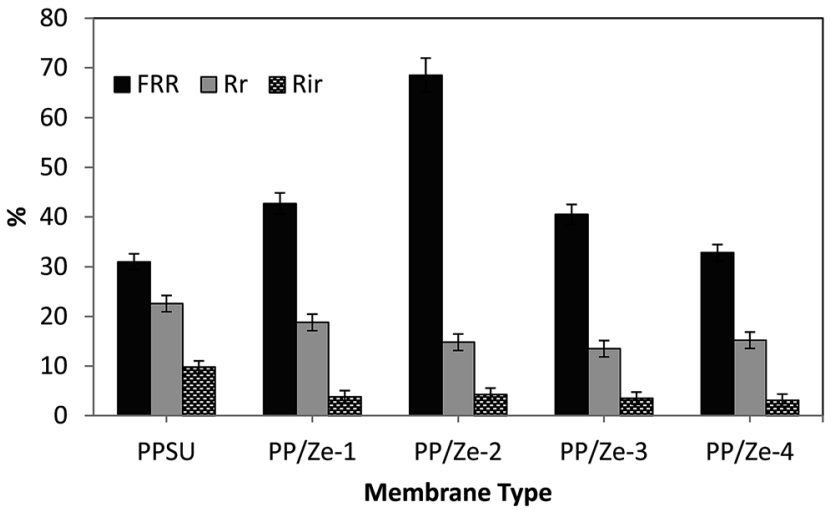

Fig. 14 Fouling properties of PP/Ze MMMs during lignin filtration.

Table 5 Fouling parameters for $\mathrm{Cu}$-zeolite and Fe-zeolite incorporated PPSU MMMs

\begin{tabular}{llllll}
\hline $\begin{array}{l}\text { Membrane } \\
\text { type }\end{array}$ & $\begin{array}{l}\text { TFI } \\
\left(\mathrm{m}^{2} \mathrm{~L}^{-1}\right)\end{array}$ & $\begin{array}{l}R_{\mathrm{m}} \times 10^{6} \\
\left(\mathrm{~m}^{-1}\right)\end{array}$ & $\begin{array}{l}R_{\mathrm{c}} \times 10^{6} \\
\left(\mathrm{~m}^{-1}\right)\end{array}$ & $\begin{array}{l}R_{\mathrm{a}} \times 10^{6} \\
\left(\mathrm{~m}^{-1}\right)\end{array}$ & $\begin{array}{l}R_{\mathrm{cp}} \times 10^{6} \\
\left(\mathrm{~m}^{-1}\right)\end{array}$ \\
\hline $\mathrm{PPSU}$ & 60.84 & 1.92 & 1.13 & 11.24 & 3.15 \\
$\mathrm{PP} / \mathrm{Ze}-1$ & 45.16 & 0.62 & 0.35 & 0.25 & 0.54 \\
$\mathrm{PP} / \mathrm{Ze}-2$ & 23.20 & 0.45 & 0.18 & 1.26 & 0.02 \\
$\mathrm{PP} / \mathrm{Ze}-3$ & 54.60 & 1.94 & 0.61 & 4.80 & 0.85 \\
$\mathrm{PP} / \mathrm{Ze}-4$ & 48.30 & 2.13 & 1.02 & 7.30 & 0.72 \\
$\mathrm{PP} / \mathrm{Cu}-\mathrm{Ze}-1$ & 55.68 & 3.19 & 3.97 & 8.77 & 0.48 \\
$\mathrm{PP} / \mathrm{Cu}-\mathrm{Ze}-2$ & 35.80 & 1.43 & 0.47 & 2.67 & 0.24 \\
$\mathrm{PP} / \mathrm{Fe}-\mathrm{Ze}-1$ & 62.35 & 22.33 & 11.24 & 10.12 & 1.32 \\
$\mathrm{PP} / \mathrm{Fe}-\mathrm{Ze}-2$ & 64.75 & 27.36 & 7.53 & 14.83 & 1.20 \\
\end{tabular}

incorporation of Fe-ZSM-5 beyond $0.25 \mathrm{wt} \%$, both the fouling resistance and the adsorption due to cake layer formation and pore blockage have increased, which is attributable to the very much lower permeance offered, owing to higher polymeric chain rigidification. In the case of Fe-ZSM-5 incorporation, the TFI value becomes higher even than that of virgin PPSU. The total fouling resistances of Cu-ZSM-5 incorporated PPSU were

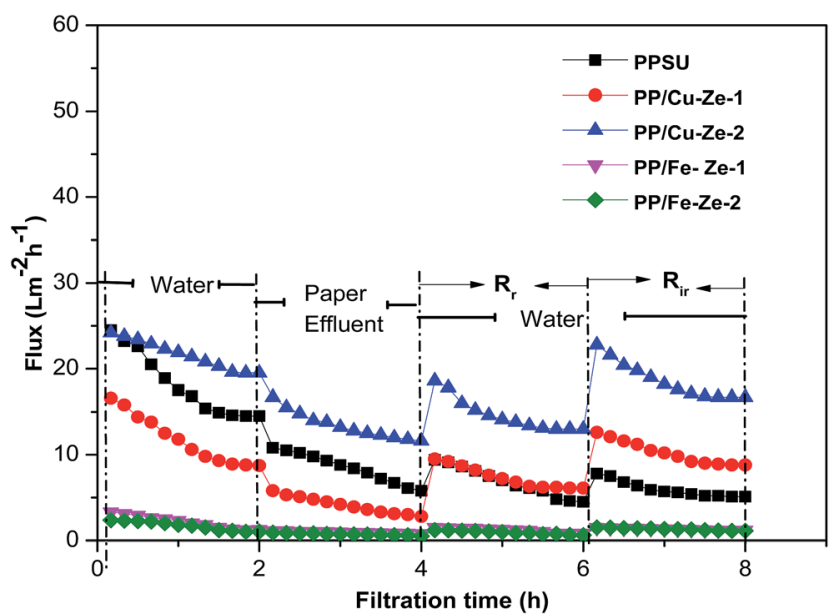

Fig. 15 Flux behaviour of PP/Cu-Ze and PE/Fe-Ze MMMs during lignin filtration.

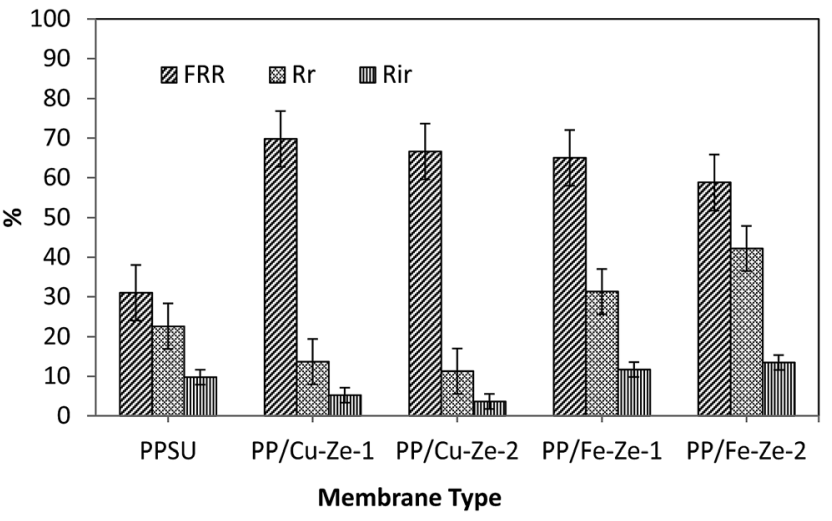

Fig. 16 Fouling properties of PP/Cu-Ze and PE/Fe-Ze MMMs during lignin filtration.

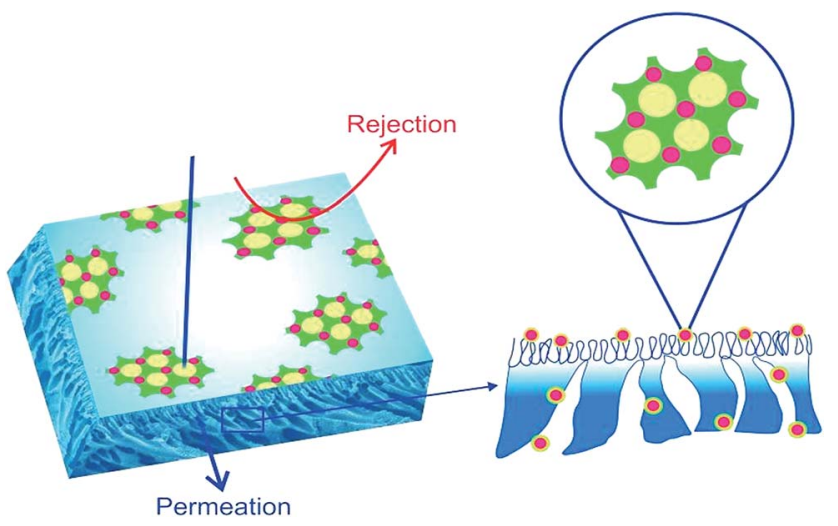

Fig. 17 Schematic illustration of functionalized zeolite incorporated MMMs.

minimal compared to virgin PPSU, which is mainly due to the increased flux recovery after chemical cleaning. The influence $\mathrm{Cu}$ and Fe ZSM on the fouling effect is illustrated in Fig. 15. The fouling ratios of each PP/FAC MMM along with their FRR\% are shown in Fig. 16. The increase in $\mathrm{FRR} \%$ of $\mathrm{PP} / \mathrm{Cu}-\mathrm{Ze}$ and $\mathrm{PP} / \mathrm{Fe}-$ Ze MMMs themselves has ensured that the anti-fouling property of $\mathrm{Cu}$ and Fe incorporated PPSU MMMs was enhanced. The $\mathrm{PP} / \mathrm{Cu}$-Ze membranes have higher FRR values, suggesting that adsorbed and deposited foulants on the membrane surfaces could be easily washed away. These results clearly demonstrate that the modification of the PPSU membranes with $\mathrm{Cu}$-zeolite improves the antifouling property of the blended membrane. The increased fouling ratio of $\mathrm{PP} / \mathrm{Fe}-\mathrm{Ze}$ is attributed to the lower permeation offered that has altogether increased the fouling ratio to twice that of the virgin PPSU membrane (Fig. 17).

\section{Conclusions}

The potential of zeolite and functionalised zeolite incorporation for improving the efficiency of PPSU MMMs has been investigated in detail. Based on the performance evaluation of synthesized MMMs, the following conclusions were arrived at: 
(1) From the characterization results of PPSU MMMs, it could be deduced that minimal addition of ZSM- 5 and Cu-ZSM5 in the wt\% concentrations of 0.25 and 0.5 has enhanced both the surface and bulk membrane properties. The reason is attributable to the lesser number of interfacial bridges between polymer and nanomaterials with minimal addition ZSM-5 and Cu-ZSM-5.

(2) The addition of 0.25 wt $\%$ of Cu-ZSM-5 in PPSU has also caused enlargement of the macro-voids in the bottom layer of the PP/Cu-Ze MMMs, which leads to higher permeability. SEMEDX line scanning was applied to analyze the Cu-ZSM-5 and FeZSM-5 particle distribution profiles on the PPSU membrane surface. The ZSM-5, Cu-ZSM-5 and Fe-ZSM-5 particles are well incorporated into the PPSU membrane and improved its hydrophilicity, pore size and permeability flux in wastewater treatment.

(3) An increase in ZSM-5, Cu-ZSM-5 and Fe-ZSM-5 particles, changes in fouling parameters and an impact on lignin rejection were observed. However, the TFI value of $23.20 \mathrm{~m}^{2} \mathrm{~L}^{-1}$ of the Fe-ZSM-5 incorporated membrane was less even compared to that of virgin PPSU. In addition, the highest value of $85.2 \%$ of lignin retention was attained at addition of $0.5 \mathrm{wt} \%$ of ZSM- 5 in PPSU MMMs.

From the results, we found that the addition of ZSM-5, CuZSM-5 and Fe-ZSM-5 particles to the casting solution induced hydrophilicity to the membrane surface and the ZSM-5 zeolite controls the movement of solutes or ions in interaction with wastewater.

\section{Acknowledgements}

Dr G. Arthanareeswaran acknowledges the Korean Federation of Science and Technology Society (KOFST) for a Brain pool fellowship (161S-5-3-1561).

\section{References}

1 Y. Li, H. M. Guan, T. S. Chung and S. Kulprathipanja, Effects of novel silane modification of zeolite surface on polymer chain rigidification and partial pore blockage in Polyethersulfone (PES)-zeolite A mixed matrix membranes, J. Membr. Sci., 2006, 275, 17-28.

2 S. M. Sanip, A. F. Ismail, P. S. Goh and T. Soga, Gas Separation Properties of Functionalized Carbon Nanotubes Mixed Matrix Membrane, Sep. Purif. Technol., 2011, 78, 208-213.

3 R. Saranya, G. Arthanareeswaran, S. Sakthivelu and P. Manohar, Preparation and Performance Evaluation of Nanokaolinite-Particle-Based Polyacrylonitrile Mixed-Matrix Membranes, Ind. Eng. Chem. Res., 2012, 51(13), 4942-4951.

$4 \mathrm{~J}$. Kim and B. V. Bruggen, The use of nanoparticles in polymeric and ceramic membrane structures: review of manufacturing procedures and performance improvement of water treatment, Environ. Pollut., 2010, 158, 2335-2349.

5 Y. Yang, H. Zhang, P. Wang, Q. Zheng and J. Li, The influence of nano-sized $\mathrm{TiO}_{2}$ fillers on the morphologies and properties of PSF UF membrane, J. Membr. Sci., 2007, 288, 231-238.
6 M. M. Pendergast and E. M. V. Hoek, A review of water treatment membrane nanotechnologies, Energy Environ. Sci., 2011, 4, 1946-1971.

7 G. Arthanareeswaran, T. K. Sriyamuna Devi, D. Mohan and M. Raajenthiren, Effect of silica particles on cellulose acetate blend ultrafiltration membranes: part I, Sep. Purif. Technol., 2008, 64, 38-47.

8 S. Kim, L. Chen, J. K. Johnson and E. Marandi, Polysulfone and functionalized carbon nanotube mixed matrix membranes for gas separation: theory and experiment, J. Membr. Sci., 2007, 294, 147-158.

9 M. Rahimpour, S. Jahanshahi, S. Khalili, A. Mollahosseini, A. Zirepour and B. Rajaeian, Novel functionalized carbon nanotubes for improving the surface properties and performance of polyethersulfone (PES) membrane, Desalination, 2012, 286, 99-107.

10 E. Celik, H. Park, H. Choi and H. Choi, Carbon nanotube blended polyethersulfone membranes for fouling control in water treatment, Water Res., 2011, 45, 274-282.

11 G. M. Shi, T. Yang and T. S. Chung, Polybenzimidazole (PBI)/ zeoliticimidazolate frameworks (ZIF-8) mixed matrix membranes for pervaporation dehydration of alcohols, J. Membr. Sci., 2012, 415-416, 577-586.

12 Y. Shen and A. C. Lua, Preparation and characterization of mixed matrix membranes based on PVDF and three inorganic fillers (fumed nonporous silica, zeolite $4 \mathrm{~A}$ and mesoporous MCM-41) for gas separation, Chem. Eng. J., 2012, 192, 201-210.

13 G. M. Rios, M. Belleville, D. P. Jeanjean and J. Sanchez, Membrane Technologies at the Service of Sustainable Development through Process Intensification, Sustain. Ind. Chem., 2009, 257-278.

14 A. Sumisha, G. Arthanareeswaran, A. F. Ismail, D. Praveen Kumar and M. V. Shankar, Functionalized titanate nanotube-polyetherimide nanocomposite membrane for improved salt rejection under low pressure nanofiltration, RSC Adv., 2015, 5, 39464-39473.

15 Y. L. Thuyavan, N. Anantharaman, G. Arthanareeswaran, A. F. Ismail and R. V. Mangalaraja, Preparation and characterization of $\mathrm{TiO}_{2}$-sulfonated polymer embedded polyetherimide membranes for effective desalinaition application, Desalination, 2015, 365, 355.

16 S. R. Panda, M. Mukherjee and S. De, Performance evaluation of two stage nanofiltration for treatment of textile effluent containing reactive dyes, J. Water. Process. Eng., 2015, 6, 93-105.

17 L. L. Hwang, J. C. Chen and M. Y. Wey, The properties and filtration efficiency of activated carbon polymer composite membranes for the removal of humic acid, Desalination, 2013, 313, 166-175.

18 Q. F. Alsalhy, J. M. Ali, A. A. Abbas, A. Rashed, B. V. Bruggen and S. Balta, Enhancement of poly(phenyl sulfone) membranes with ZnO nanoparticles, Desalin. Water Treat., 2013, 51, 6070-6081.

19 P. D. Peeva, T. Knoche, T. Pieper and M. Ulbricht, Cross-flow ultrafiltration of protein solutions through unmodified and surface functionalized polyethersulfone membranes - 
effect of process conditions on separation performance, Sep. Purif. Technol., 2012, 92, 83-92.

20 J. S. Taurozzi, H. Arul, V. Z. Bosak, A. F. Burban, T. C. Voice, M. L. Bruening and V. V. Tarabara, Effect of filler incorporation route on the properties of polysulfone-silver nanocomposite membranes of different porosities, J. Membr. Sci., 2008, 325, 58-68.

$21 \mathrm{~B}$. V. Bruggen, Chemical modification of polyethersulfonenanofiltration membranes: a review, J. Appl. Polym. Sci., 2009, 114, 630-642.

22 E. M. V. Hoek, A. K. Ghosh, X. Huang, M. Liong and J. I. Zink, Physical-chemical properties, separation performance, and fouling resistance of mixed-matrix ultrafiltration membranes, Desalination, 2011, 283, 89-99.

23 B. Seoane, J. Coronas, I. Gascon, M. E. Benavides, O. Karvan, J. Caro, F. Kapteijn and J. Gascon, Metal-organic framework based mixed matrix membranes: a solution for highly efficient $\mathrm{CO}_{2}$ capture, Chem. Soc. Rev., 2015, 44, 2421-2454.

24 A. F. Ismail, R. Norida, W. A. W. A. Rahman, T. Matsuura and S. A. Hashemifar, Preparation and characterization of hyperthin-skinned and high performances asymmetric polyethersulfone membrane for gas separation, Desalination, 2011, 273, 93-104.

25 M. Ahmaruzzaman, A review on the utilization of fly ash, Prog. Energy Combust. Sci., 2010, 36, 327-363.

26 S. Babel and T. A. Kurniawan, Low-cost adsorbents for heavy metals uptake from contaminated water: a review, J. Hazard. Mater., 2003, 97, 219-243.

27 C. V. Funk and D. R. Lloyd, Microporous mixed matrix (ZeoTIPS) membranes: prediction of gas separation performance, J. Membr. Sci., 2008, 313, 224-231.

28 L. E. M. Gevers, I. F. J. Vankelecom and P. A. Jacobs, Zeolite filled polydimethylsiloxane (PDMS) as an improved membrane for solvent-resistant nanofiltration (SRNF), Chem. Commun., 2005, 19, 2500-2516.

$29 \mathrm{D}$. Li and H. Wang, Recent developments in reverse osmosis desalination membranes, J. Mater. Chem., 2010, 20, 4551-4566.

30 G. Arthanareeswaran, P. Thanikaivelan and M. Raajenthiren, Sulfonated poly(ether ether ketone) induced porous poly(ether sulfone) blend membranes for separation of protein and metal ions, J. Appl. Polym. Sci., 2010, 116, 9951004.
31 G. Hurwitz, G. R. Guillen and E. M. V. Hoek, Probing polyamide membrane surface charge, zeta potential, wettability, and hydrophilicity with contact angle measurements, J. Membr. Sci., 2010, 349, 349-357.

32 A. Marmur, Equilibrium contact angles: Theory and measurement, Colloids Surf., A, 1996, 116, 55-72.

33 M. Kumar and M. Ulbricht, Advanced ultrafiltration membranes based on functionalized poly(arylene ether sulfone) block copolymers, RSC Adv., 2013, 3, 12190-12203.

34 K. C. Khulbe, C. Y. Feng and T. Matsuura, Synthetic Polymeric Membranes Characterization by Atomic Force Microscopy, Springer Laboratory Manuals in Polymer Science, Springer Publishing, New York, 2007.

35 M. P. Pina, R. Mallada, M. Arruebo, M. Urbiztondo, N. Navascues, O. de la Iglesia and J. Santamaria, Zeolite films and membranes. Emerging applications, Microporous Mesoporous Mater., 2011, 144, 19-27.

36 M. J. Han and S. T. Nam, Thermodynamic and rheological variation in polysulfone solution by PVP and its effect in the preparation of phase inversion membrane, J. Membr. Sci., 2002, 202, 55-61.

37 R. S. Hebbar, A. M. Isloor, A. F. Ismail, S. J. Shilton, A. Obaid and H. K. Fun, Probing the morphology and anti-organic fouling behaviour of a polyetherimide membrane modified with hydrophilic organic acids as additives, New J. Chem., 2015, 39, 6141-6150.

38 D. Q. Vu, W. J. Koros and S. J. Miller, Mixed Matrix Membranes Using Carbon Molecular Sieves I. Preparation and Experimental Results, J. Membr. Sci., 2003, 211, 311-334.

39 G. T. Vuong and T. O. Do, A new route for the synthesis of uniform nanozeolites with hydrophobic external surface in organic solvent medium, J. Am. Chem. Soc., 2007, 129, 3810-3811.

40 T. S. Chung, L. Y. Jiang, Y. Li and S. Kulprathipanja, Mixed matrix membranes (MMMs) comprising organic polymers with dispersed inorganic fillers for gas separation, Prog. Polym. Sci., 2007, 32, 483-507.

41 S. G. Adoor, L. S. Manjeshwar, S. D. Bhat and T. M. Aminabhavi, Aluminum-rich zeolite beta incorporated sodium alginate mixed matrix membranes for pervaporation dehydration and esterification of ethanol and acetic acid, J. Membr. Sci., 2008, 318, 233-246. 